\title{
A holistic inverse approach based on a multi-objective function optimisation model to recover elastic-plastic properties of materials from the depth-sensing indentation test
}

\author{
O. Iracheta, C. J. Bennett*, W. Sun
}

Gas Turbine and Transmissions Research Centre, Faculty of Engineering, University of Nottingham, Nottingham NG7 2RD, United Kingdom.

\footnotetext{
*chris.bennett@nottingham.ac.uk
}

Keywords: Inverse analysis of $P$ - $h$ curves, pile-up and sink-in effects, indentation size effect

\begin{abstract}
Recent years have seen an increased interest in the mechanical characterisation of materials via the inverse analysis of depth-sensing indentation data; however, at low-loads both the reaction forces measured by the instrument and the contact evolution at the indenter-material interface may be severely affected by indentation size effects (ISEs). Notwithstanding the knowledge of ISE, the inverse analyses proposed to date have failed to investigate the divergence between the smallscale properties measured via indentation and the large-scale properties extracted from other techniques, e.g. tensile testing. Therefore, this study investigates the sensitivity of an inverse analysis methodology to the indentation size in relation to the size of the microstructure. The proposed inverse analysis approach is based on a multi-objective function (MOF) optimisation model that finds the combination of material properties (Young's modulus, yield stress and strain-hardening exponent) that provides the best fit to both the experimental load-displacement $(P-h)$ curve extracted from the indentation instrument and pile-up profile of the residual imprint measured with an atomic force microscope. Therefore, the piling-up/sinking-in effect, which is strongly linked to the plastic hardening behaviour of the indented material, is considered to address the non-uniqueness issue of the inverse analysis of indentation. A Berkovich indenter was used to measure the near surface properties of three different materials, including a titanium alloy (Ti-6Al-4V), chromium-molybdenum-vanadium steel $(\mathrm{CrMoV})$ and high purity copper (C110); materials have been selected to represent a wide range of ductile metallic materials so as to assess the generality of the MOF model.
\end{abstract}




\section{Introduction}

Depth-sensing indentation has become a common technique to study the elastic and plastic behaviour of materials owing to its capability of measuring very small volumes of material while inflicting minimal damage to the sample. The test involves pressing a hard indenter into a solid body by applying either a controlled load or displacement and recording the response such that a load-depth $(P-h)$ curve is extracted. The Oliver-Pharr method is a primary technique for determining hardness and elastic modulus from the predicted contact area; however, the derivation is based on Sneddon's [1] work of elastic indentation and therefore is limited to materials that sink-in. The sink-in effect is more pronounced for strain-hardening or non-strain hardening materials with a low value of $E / \sigma_{y}$ and involves material flowing inward and downwards as the plastically displaced material is accommodated mainly by far-field elastic displacements. By contrast, non-strain-hardening materials with a high value of $E / \sigma_{y}$ deform more locally causing plastically displaced material to pile-up around the indenter due to the incompressibility of plastic deformation [2]. This is schematically illustrated in Figure 1.

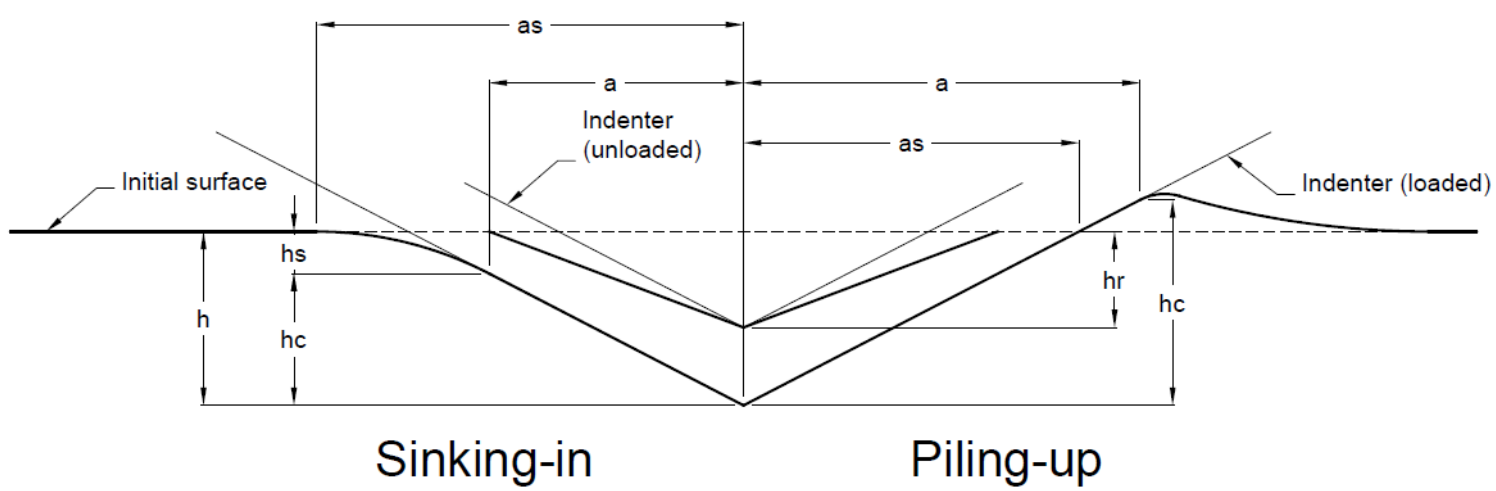

Figure 1. Schematic diagram of the surface profile at loading and unloading for indenter

Therefore, both the elastic recovery and the indentation deformation behaviour contribute to the uncertainty in predicting the actual contact area of indentation and consequently in the determination of material properties. Errors of up to $60 \%$ in the prediction of the actual contact area and consequently a deviation of up to 60 and $50 \%$ in the calculations of hardness and Young's modulus respectively could be expected for materials in which pile-up is significant [3]. A study conducted by N'jock et al. [4] concluded that a better approximation to the actual contact area when piling-up predominates is achieved following the method proposed by Loubet et al. [5]; the maximum error in the value of the reduced Young's modulus of five different materials that exhibited pile-up deformation mode was found to be at least $50 \%$ 
smaller compared to the value predicted by the Oliver-Pharr method. Recent advances in computational capacities have allowed the development of (forward) finite element models to study the solid mechanical foundations of the indentation problem [6-8]. Inverse analysis methods have been developed more recently to recover elastic-plastic material properties from $P-h$ curves. The methodologies available to date to relate the mechanical properties of a material to the indentation $P$ - $h$ curve can be categorised into three main groups: A first group provides empirical-analytical relationships derived from either Sneddon's solution to elastic indentation, e.g. $[5,9,10]$, or the finite element solutions to the indentation problem, e.g. [8, 11-13]. A second group employs finite element calculations and the $\Pi$ theorem [14] in dimensional analysis to derive the set of dimensionless functions that define the shape of the $P$ - $h$ curve in terms of the mechanical properties of the indented material, e.g. [15-17]. The third group relies on the optimisation theory in order to find the set of mechanical properties that provide the best fit between a target and a predicted $P$ - $h$ curve; both empirical-analytical formulae, e.g. [18, 19], and the FE approach, e.g. [20, 21], have been adopted to define the predicted $P$ - $h$ curve; however, the main concern with these approaches purely based on the $P$ $h$ curve is the existence of different materials that exhibit an identical mechanical response to indentation, i.e. the so-called 'mystical' materials [22]. The solution to the inverse analysis of indentation is not unique as a consequence of different factors such as the difficulties in representing numerically the complex strain field developed under the indenter during indentation, the existence of an intrinsic relationship among the characteristic parameters that can be established from a $P$ - $h$ curve $[23,24]$ and its low sensitivity to the plastic properties of the material $[13,25]$. A few authors have explored the gains attained by measuring the residual imprint in addition to the $P$ - $h$ curve. The work presented by Bolzon et al. [26] using pseudoexperimental data (FE simulated) concluded that information from residual imprints improves the optimisation of material properties. The objective function was defined as follows:

$$
w(\mathbf{z})=\alpha \sum_{i=1}^{N_{h}}\left(\frac{h_{i}^{\text {exp }}-h_{i}^{\text {com }}(\mathbf{z})}{h_{\max }^{\text {exp }}}\right)^{2}+\beta \sum_{j=1}^{N_{u}}\left(\frac{u_{j}^{\text {exp }}-u_{j}^{\text {com }}(\mathbf{z})}{u_{\max }{ }^{\exp }}\right)^{2}
$$

where the subscripts exp and com refer to experimental and computed quantities, respectively, $h_{i}$ is the indentation depth at a force $i$ and $u_{j}$ the displacement at a point $j$ from the axis of symmetry. The factors $\alpha$ and $\beta$ take a value of $1(\alpha=\beta=1)$ to include both the data from the $P$ - $h$ curve and residual imprint. In a further study [27], experimental residual imprints of a Rockwell hardness test at macro-scale $\left(h_{\max }=260 \mu \mathrm{m}\right)$ in a pipeline steel were measured using 
a contact profilometer. A genetic algorithm was invoked to minimise Equation 1; the mean values of the identified properties by means of the suggested approach, deviated between 17.8 $-20.9 \%$ and $5.6-16.7 \%$ from the experimental values of $E$ and $\sigma_{y}$. Moy et al. [28] adapted Bolzon's [26] function by using only the value of maximum pile-up $\left(h_{\text {pile-up }}\right)$ and therefore the second term in Equation 1 was modified accordingly. The minimisation was performed using a trust region algorithm. The elastic-plastic properties $\left(E, \sigma_{y}\right.$ and $\left.n\right)$ of an $\mathrm{Al} 2024$ alloy in the as-received and two age-hardened conditions were investigated. The inclusion of the maximum pile-up height significantly improved the prediction of the material properties, particularly the discrepancies between the predicted and experimental value of $n$ and $\sigma_{y}$ decreased from a maximum of $64.29 \%$ to $7.61 \%$ and from 38.75 to $11.75 \%$, respectively. For the case of $E$, the improvement was less marked with errors reduced from a maximum of 11.70 to $10.79 \%$. These studies [26-28] used a sphero-conical indenter and consequently a 2D axisymmetric formulation was proposed. It is apparent that many authors are more concerned in the development of new or different approaches to conduct an inverse analysis than on the study of the virtues and disadvantages of those available; therefore, this paper discusses in detail the capabilities of a MOF model coupled with a continuum mechanics FE approach to recover elastic-plastic properties of three polycrystalline materials. Furthermore, although different mechanisms that produce a sensitivity of microhardness to indentation size effects have been reported in the literature for at least thirty years [29], it appears that there is little awareness regarding the gap between the mechanical response to indentation at different scales. Therefore, this paper discusses the potential risks of attempting to recover mechanical properties when the indentation size is of the same order of magnitude as the microstructural features of the tested material.

\section{Experimental methods}

\subsection{Materials and metallographic preparation}

Three materials with different elastic-plastic behaviour, including moderate strain-hardening (CrMoV steel), a low strain-hardening (Ti-6Al-4V) and an elastic-perfectly plastic (C110 copper) material, have been selected to represent a wide range of ductile metallic materials so as to assess the generality of the MOF model. The material composition is included in Table 1. $\mathrm{CrMoV}$ steel was used in the tempered martensite condition and therefore the as-received sample was austenitized at $940{ }^{\circ} \mathrm{C}$ for 45 minutes, oil quenched and tempered at $570{ }^{\circ} \mathrm{C}$ for 120 minutes. 


\begin{tabular}{cccc}
\hline \multicolumn{4}{c}{$\begin{array}{c}\text { Table 1. Chemical composition of studied materials } \\
\text { (weight \%) as per a) }\end{array}$} \\
materials and c) VSMPO-Trias. \\
\hline & $\mathbf{C 1 1 0}^{\mathbf{a}}$ & $\mathbf{C r M O V}^{\mathbf{b}}$ & Ti-6Al-4V \\
$\mathrm{Cu}$ & 99.99 & - & - \\
$\mathrm{Pb}$ & 0.001 & - & - \\
$\mathrm{P}$ & 0.0003 & 0.020 & - \\
$\mathrm{S}$ & 0.002 & 0.020 & - \\
$\mathrm{C}$ & - & $0.35-0.43$ & - \\
$\mathrm{Si}$ & - & $0.10-0.35$ & - \\
$\mathrm{Cr}$ & - & $3.0-3.5$ & - \\
$\mathrm{Mo}$ & - & $0.80-1.10$ & - \\
$\mathrm{Ni}$ & - & 0.30 max & - \\
$\mathrm{Sn}$ & - & 0.03 & - \\
$\mathrm{Mn}$ & - & $0.40-0.70$ & 0.01 \\
$\mathrm{~V}$ & - & $0.15-0.25$ & 4.04 \\
$\mathrm{Ti}$ & - & - & 88.83 \\
$\mathrm{Fe}$ & - & - & 0.14 \\
$\mathrm{Al}$ & - & - & 6.85 \\
$\mathrm{Nb}$ & - & - & 0.03 \\
\hline
\end{tabular}

Flat specimens of $\mathrm{CrMoV}$, Ti-6Al-4V and C110 were mounted in a conductive resin and then ground with abrasive paper down to 1200 grit $(15.3 \mu \mathrm{m})$, followed by polishing with 5 and 1 $\mu \mathrm{m}$ diamond suspension. Ultimately, specimens were polished with colloidal silica down to $0.06 \mu \mathrm{m}$ for a minimum of 20 minutes, in order reduce the size of the hardened layer formed due to mechanical polishing.

\subsection{Mechanical testing at macro- and micro-scale}

At least two tensile test specimens were prepared from each material and tested as per ASTM E8/E8M-15a [30] to characterise their bulk properties (macro-scale). Due to the condition of supply, flat specimens were cut via electrical discharge machining (EDM) from a $3 \mathrm{~mm}$ sheet of Ti-6Al-4V and round specimens were machined from $25.4 \mathrm{~mm}$ bars of both $\mathrm{CrMoV}$ and C110. All specimens were tested in an Instron Servohydraulic Test Machine at room temperature and crosshead velocity of $0.25 \mathrm{~mm} / \mathrm{min}$ (strain rate $\sim 10^{-4} \mathrm{~s}^{-1}$ ) in order to ensure quasi-static conditions.

Depth-sensing indentation tests were conducted using a Micro Materials Ltd. NanoTest ${ }^{\mathrm{TM}}$ NTX equipped with a Berkovich indenter. A new Berkovich diamond indenter with a tip radius of less than $20 \mathrm{~nm}$ has been used to perform the indentation. Before testing, both the indenter area 
function and the load frame compliance were calibrated using a standard sample of fused silica in compliance with ISO 14577 [31]. In order to remove the effects of surface roughness on the results, indentation loads were selected to reach maximum indentation depths of at least 20 times the average roughness $\left(R_{a}\right)$ of the specimen in accordance with ISO14577 [31]. Given that the polishing procedure affects the surface of the specimen to a depth of about the nominal grit size, due to strain-hardening or cold-working [2], indentations were performed at sufficient load to ensure indentation depths of at least three times the thickness of the strain-hardened layer as suggested by Liu et al. [32]. Therefore, the indenter has been loaded from an initial contact force $\left(P_{i}\right)$ of $0.1 \mathrm{mN}$ to a maximum force $\left(P_{\max }\right)$ of $240 \mathrm{mN}$ at a loading and unloading rate of $10 \mathrm{mN} / \mathrm{s}$ for $\mathrm{CrMoV}$ and Ti-6Al-4V. In order to investigate the mechanical response at a lower scale, CrMoV was also loaded to $120 \mathrm{mN}$ at the same rate of $10 \mathrm{mN} / \mathrm{s}$. C110 on the other hand was loaded to $120 \mathrm{mN}$ at a rate of $4 \mathrm{mN} / \mathrm{s}$ in order to obtain a similar number of data points. In specimens of $\mathrm{CrMoV}$, a dwell period of $30 \mathrm{~s}$ at $P_{\max }$ was applied so as to ensure the unloading data used for analysis purpose were mostly elastic. In addition, the load was held constant for a period of $30 \mathrm{~s}$ at $0.1 P_{\max }$ to establish the rate of displacement produced by thermal expansion in the system, that is, thermal drift, allowing thermal drift corrections to be performed on these curves; however, due to the complications in the inverse analysis caused by a non-continuous $P$ - $h$ curve, this load-time sequence was avoided in C110 and Ti-6Al-4V and instead, a single loading and unloading ramp was defined. Sets of five indentations were performed per indentation test, at an offset of at least 20 times the maximum depth as suggested by ASM International [33].

\subsection{Surface topography measurements}

The residual imprints of the indents of interest were measured using a Bruker FastScan Bio Icon atomic force microscope (AFM) in peak force mode. As it was impractical to analyse every indentation for a given set of indentation parameters, surface topography measurements were taken only from the indents which exhibited the highest (HS) and lowest stiffness (LS) for each set of indentations. Furthermore, from each pair of measurements, only the indentation with the best agreement between the depth measured via the indentation instrument and AFM has been selected as input data for the optimisation procedure. Three pile-up profiles were extracted from each indentation, i.e. one per each of the directions of the bisector of the side of the triangular impression. However, in order to prove the enhanced capabilities of the MOF model to converge to the constitutive properties of the indented material only the most 
characteristic pile-up pattern has been selected for the optimisation analysis presented in section 4.2.2. That is, the one showing the smoother transition from maximum pile-up to free

surface. Notwithstanding, section 5 discusses on the sensitivity of the optimisation solution to the direction of the pile-up profile used as a second objective. Owing to the equivalency of the projected areas, the same parameters were defined to measure the surface topography regardless of the material, i.e. 512 lines of 512 sample data points per scan line, scanned in a squared frame between 20 to $25 \mu \mathrm{m}$ at a scan rate of half a line per second $(0.5 \mathrm{~Hz})$. Bruker RTESPA-300 etched silicon probes with tip radii in the range 8 to $12 \mathrm{~nm}$, as per the manufacturers' specifications, were used. A cantilever coated with Al reflective was employed, as recommended for highly reflective samples, with a spring constant of $40 \mathrm{~N} / \mathrm{m}$. Before analysing the height measurements, a first-order plane fit was applied to the heights of each pixel in the image in order to correct for tilting. Roughness statistics were reported from areas neighbouring the residual imprint following the ISO 4287/1-1997 [34] standard.

The residual imprint area was quantified as the area beneath the free (reference) surface; however, due to the highly irregular topography of Ti-6Al-4V, the reference depth was offset to $-100 \mu \mathrm{m}$ from the free surface in this case.

\section{Numerical methods}

\subsection{Finite element modelling of the indentation test with a Berkovich tip}

The indentation test of a bulk metal has been numerically simulated in this study using the ABAQUS Standard 6.12-3 FE code. The model assumes a rigid indenter pressed into an isotropic, elastic-plastic, rate independent, semi-infinite body under quasi-static and isothermal conditions. A homogenous constitutive behaviour was assumed for the indented body and therefore the model is valid only for indentation tests carried out at sufficiently deep indentation depths so that the effects of the characteristic microstructural size parameters are negligible. The material constitutive model follows a Swift power law hardening rule,

$$
\begin{gathered}
\sigma=E \varepsilon, \quad \text { for } \varepsilon \leq \frac{\sigma_{y}}{E} \\
\sigma=K \varepsilon^{n}, \quad \text { for } \varepsilon \geq \frac{\sigma_{y}}{E}
\end{gathered}
$$


where $E$ is the Young's modulus, $\sigma_{y}$ the initial yield stress corresponding to the yield strain $\varepsilon_{y}$, $n$ the work-hardening exponent, and $K$ is the strength coefficient of the indented body. Given that the Berkovich indenter is a triangular-based pyramid, only a sixth of the body has been modelled as illustrated in Figure 2. The Berkovich indenter has been modelled as a 3D discrete rigid body using 3-node 3D rigid triangular facet elements (R3D3 in ABAQUS). The specimen was defined as a 3D deformable body and has been discretised using linear tetrahedral elements (C3D4 in ABAQUS) owing to their capability to approximate complex boundaries, such as the plasticised material around the indenter. Hexahedral shaped elements with reduced integration were also tested; however, due to the imposed large rotations beneath the indenter, hourglass modes were observed. Full integration elements eliminated the mesh instabilities, yet the solution was penalised in computation time. Computations using tetrahedral and hexahedral elements, both with reduced and full integration, provided consistent results. Beneath the indenter, where steep strain gradients are expected, a finer mesh size of $0.2 \mu \mathrm{m}$ was defined based on the results of a convergence study as illustrated in Figure 3. Boundary conditions on the deformable body (specimen) were defined as follows: The displacement of nodes on Plane $I$ that come in contact with the indenter, is governed by a master-slave surface-to-surface boundary condition with zero friction as the effect of friction on the indentation process can be assumed to be negligible [11]. The nodes in the planes of symmetry (II and III) and bottom surface $(I V)$ can only deform in their own planes and the cylindrical surface $V$ is traction free. The FE solution was confirmed insensitive to far-field effects by comparing the results with that of a model constrained with a roller boundary condition $(\mathrm{U} 1=\mathrm{U} 3=0)$ on surface $V$. Load and displacement boundary conditions were imposed to the indenter such that the rigid body was only allowed to translate in the vertical direction $(\mathrm{U} 1=\mathrm{U} 3=\mathrm{UR} 1=\mathrm{UR} 2=\mathrm{UR} 3=0)$. 

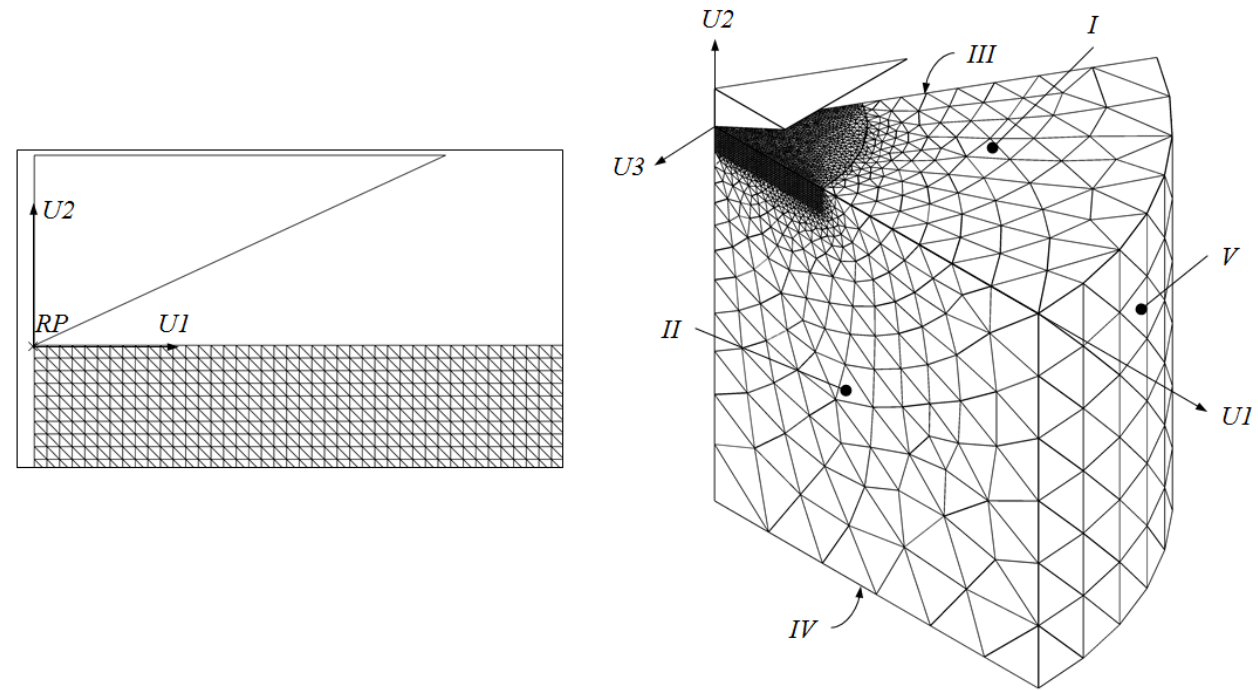

Figure 2. Geometry and boundary conditions defined in the 3D indentation model

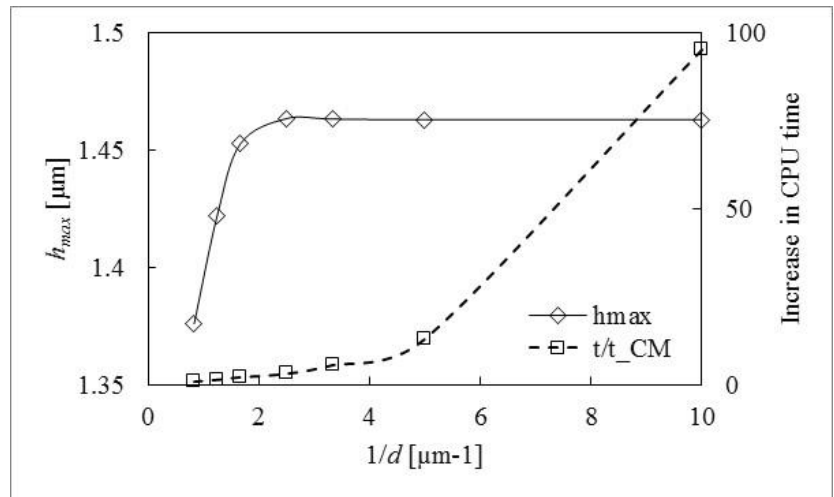

Figure 3. Sensitivity of $h_{\max }$ to the mesh size at the contact zone. CM refer to the coarsest mesh.

\subsection{Development of a multi-objective function optimisation model to solve the inverse analysis of indentation}

The optimisation problem was designed to minimise the error between both the experimental and predicted $P$ - $h$ curves, i.e. the first objective $\left(f_{l}(\boldsymbol{x})\right)$, and pile-up profiles, i.e. the second objective $\left(f_{2}(\boldsymbol{x})\right)$, as derived in Equation 3. 


$$
f(\boldsymbol{x})=\left[\begin{array}{l}
\sum_{k=1}^{N} f_{1}(\boldsymbol{x}) \\
\sum_{l=1}^{M} f_{2}(\boldsymbol{x})
\end{array}\right]^{2}
$$

where

$$
\begin{gathered}
f_{1}(\boldsymbol{x})_{k}=c \cdot\left[h_{k}{ }^{\text {exp }}-h(\boldsymbol{x})_{k}{ }^{\text {pre }}\right] \\
f_{2}(\boldsymbol{x})_{l}=(1-c) \cdot\left[y_{l}{ }^{\text {exp }}-y(\boldsymbol{x})_{l}{ }^{\text {pre }}\right]
\end{gathered}
$$

subject to

$$
\begin{gathered}
x=\left[E, \sigma_{y}, n\right]^{T} \\
x_{j}{ }^{L} \leq x_{j} \leq x_{j}{ }^{U}, \quad j=1,2,3
\end{gathered}
$$

The vector $\boldsymbol{x}$ contains the optimisation parameters, i.e. the values of the material properties, and $f(\boldsymbol{x})$ is the objective function to be minimised. The space of possible solutions has been limited by a set of bound constraints, where $x_{j}^{L}$ and $x_{j}^{U}$ represent the lower and upper boundaries of $x_{j}$. The model can be considered a multi-objective function optimisation since $f(x)$ is the weighted sum of squares between two sets of experimental (exp) and predicted data (pre), i.e. those related to the $P$ - $h$ curve and pile-up profile stored respectively in vectors $f_{1}(\boldsymbol{x})$ and $f_{2}(\boldsymbol{x})$. Therefore, $h_{k}$ is the indentation depth at a load step $k, y_{l}$ the axial coordinate of the residual imprint at the corresponding radial coordinate stored in data point $l$. Both physical data extracted from experimental indentation and FE simulated data have been linearly interpolated in order to evaluate the objective function at the specific sample points, i.e. $k$ and $l$. Experimental height measurements along the pile-up profile were interpolated at intervals between 350 and $500 \mathrm{~nm}$ to ensure a reasonable number of data points $M$. Linear interpolation of more than one point within two experimental data points was avoided. Bearing in mind that the capabilities of the indentation sensing instrument allows significantly more data points $(N)$ to be generated to define the $P$ - $h$ curve compared with those to define the pile-up profile, scaling coefficients have been introduced with the purpose of controlling the contribution of each objective function to the squared 2-norm of the residual. With the aim of keeping the number of calibration parameters to a minimum, and given that both measurements, i.e. the displacement of both the indenter and material along an edge of the indenter in the U2 direction, are of the same order of magnitude, it is reasonable to define the sum of the scaling coefficients equal to unity. 
Therefore, the components of both $f_{1}(\boldsymbol{x})$ and $f_{2}(\boldsymbol{x})$ are 'artificially' reduced by $c$ and $1-c$, respectively, with the purpose of equilibrating the global contribution of each objective function. Based on the outcome of a methodological assessment [38] $c$ was set to either 0.25 or 0.5 and the ratio of $N / M$ was kept between 2 and 7.5 to ensure the solution is insensitive to the number of data points.

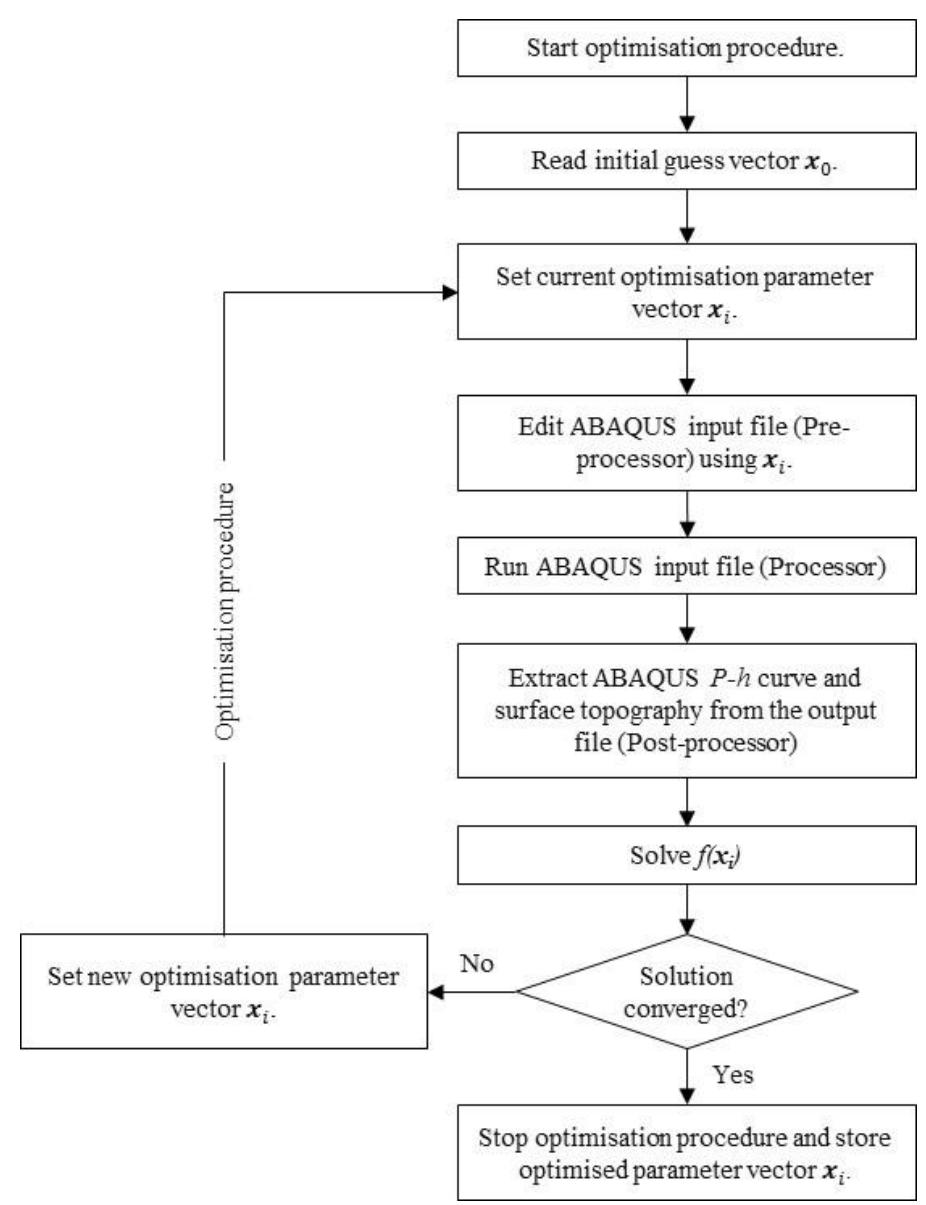

Figure 4. Flow chart of the multi-objective function optimisation procedure.

\section{Results}

\subsection{Characterisation of 'mystical' materials}

Several authors have reported the existence of materials that yield indistinguishable $P$ - $h$ curves regardless of the difference in the constitutive parameters and indenter geometry [18, 39-41], which implies that the number of possible solutions to the inverse analysis of indentation purely based on experimentally obtained $P$ - $h$ curves is infinite. The mystical materials illustrated in 
Figure 5 exhibit very different elastic and plastic behaviours, yet the coefficient of variation between $P$ - $h$ curves is expected to be less than $0.5 \%$ [41]. Details of the constitutive parameters that define the stress-strain curves are included in Table 2 . The capability of the proposed optimisation model to distinguish between mystical materials has been tested by forcing a condition of best fit between the target and predicted curve, such that the initial point is a local minimum; therefore, the inverse analysis is run using a (FE simulated) target $P$ - $h$ curve that corresponds to the mechanical properties of material A, i.e. here the target properties, whereas the initial guess vector corresponds to the properties of material B, as detailed in Table 2 .

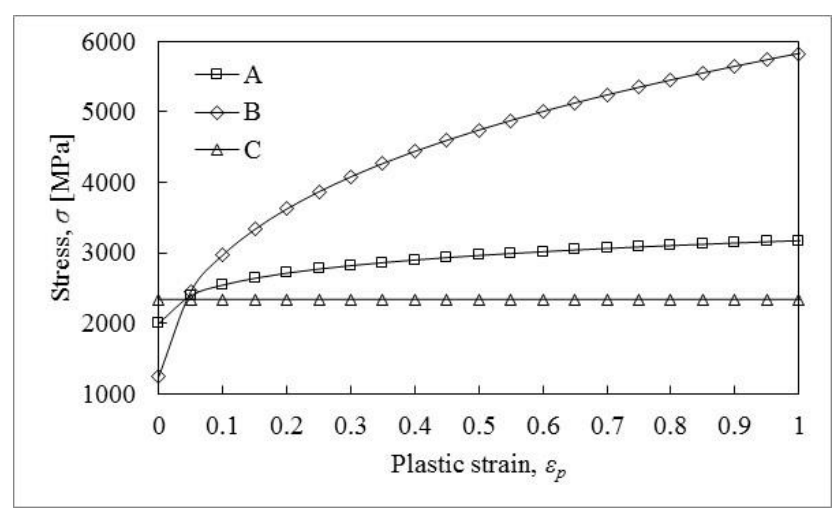

Figure 5. Different elastic-plastic materials that yield indistinguishable $P$ - $h$ curves, i.e. mystical materials [41].

Table 2. Sets of dissimilar mechanical properties that exhibit identical indentation response, i.e. mystical materials.

\begin{tabular}{cccc}
\multicolumn{4}{c}{ Parameter } \\
Material & $\boldsymbol{E}$ & $\boldsymbol{\sigma}_{\boldsymbol{y}}$ & $\boldsymbol{n}$ \\
\hline A & 200000 & 2000 & 0.1 \\
B & 212900 & 1245 & 0.3 \\
C & 192570 & 2340 & 0 \\
\hline
\end{tabular}

As shown in Figure 6a, the single-objective function (SOF) model was incapable of converging to the target properties since the information provided solely by the $P$ - $h$ curve is limited. On the other hand, the non-uniqueness issue of the inverse analysis of indentation was positively addressed by the multi-objective function (MOF) model as the additional information regarding surface topography is linked with the plastic behaviour of the material. The enrichment of the model allowed the optimisation algorithm to circumvent the local minimum and converge to the target properties as seen in Figure $6 \mathrm{~b}$. The same positive outcome was 
observed using the properties of material $\mathrm{C}$ (Table 2) as the initial guess vector. The results of the optimisations concerning the SOF and MOF models, presented in Table 3, highlights the superior performance of the proposed approach over the more conventional SOF. The $P-h$ curve is insensitive to the plastic properties, in particular to the strain-hardening exponent, and hence the SOF model, which lacked information to search for a better solution, resulted in errors of 5.2, 38.9 and $200 \%$ in $E, \sigma_{y}$ and $n$ respectively, while the MOF model reduced the errors to $0.14 \%$ in $E, 0.15 \%$ in $\sigma_{y}$ and $0 \%$ in $n$ as shown in Table 3.

a)

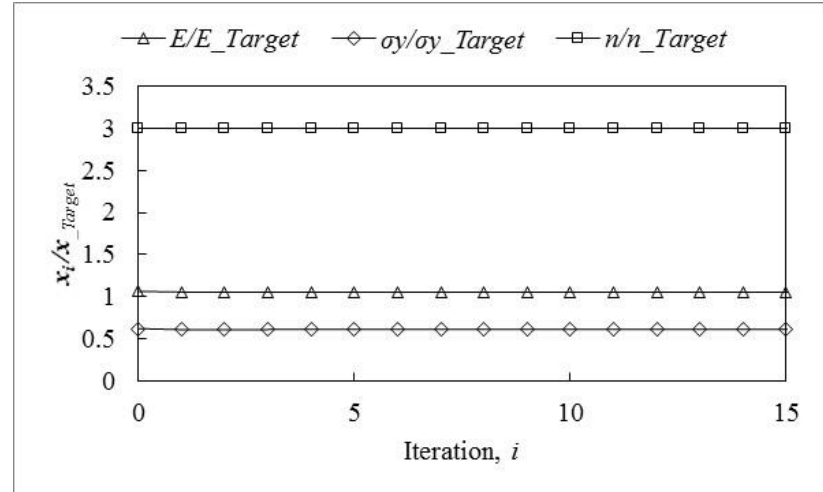

b)

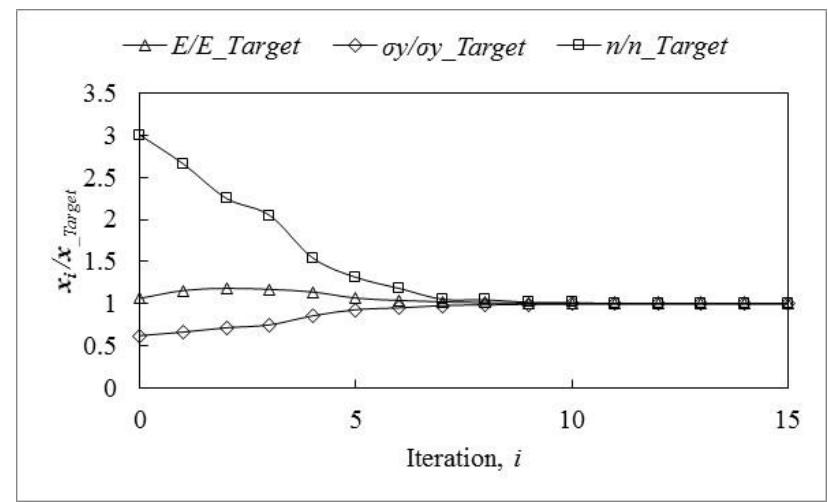

Figure 6. Iteration history through a a) SOF and b) MOF optimisation model using material $\mathrm{B}$ as the initial guess parameters. 
Table 3. Set up and results for optimisation of mystical materials

\begin{tabular}{ccccccc}
\hline \hline Model & Parameter & $\begin{array}{c}\text { Target } \\
\text { properties }\end{array}$ & $\begin{array}{c}\text { Initial } \\
\text { guess }\end{array}$ & $\begin{array}{c}\text { Bound } \\
\text { constraints }\end{array}$ & $\begin{array}{c}\text { Optimised } \\
\text { properties }\end{array}$ & $\begin{array}{c}\text { Error } \\
{[\%]}\end{array}$ \\
\hline \hline \multirow{2}{*}{ SOF } & $E[\mathrm{MPa}]$ & 200000 & 212900 & $\geq 0$ & 210468 & 5.2 \\
& $\sigma_{y}[\mathrm{MPa}]$ & 2000 & 1245 & $\geq 0$ & 1223 & 38.9 \\
& $n$ & 0.1 & 0.3 & $0-1$ & 0.3 & 200 \\
\hline \multirow{3}{*}{$\mathrm{MOF}$} & $E[\mathrm{MPa}]$ & 200000 & 212900 & $\geq 0$ & 200287 & 0.14 \\
& $\sigma_{y}[\mathrm{MPa}]$ & 2000 & 1245 & $\geq 0$ & 1997 & 0.15 \\
& $n$ & 0.1 & 0.3 & $0-1$ & 0.1 & 0 \\
\hline \multirow{3}{*}{ MOF } & $E[\mathrm{MPa}]$ & 200000 & 192570 & $\geq 0$ & 199968 & 0.02 \\
& $\sigma_{y}[\mathrm{MPa}]$ & 2000 & 2340 & $\geq 0$ & 2001 & 0.05 \\
& $n$ & 0.1 & 0 & $0-1$ & 0.1 & 0 \\
\hline \hline
\end{tabular}

\subsection{Determination of elastic-plastic material properties from $P$ - $h$ curves extracted experimentally from depth-sensing indentation test and surface profiles}

\subsubsection{Input data and model set-up}

Figure 7 includes the highest- (HS) and lowest-stiffness (LS) $P$ - $h$ curves for the set of indentations performed on $\mathrm{CrMoV}$ steel, C110 copper and Ti-6Al-4V. As previously mentioned, the displacement measured by the depth-sensing indentation instrument has been corrected for frame compliance in order to ensure that the contact stiffness is that of the specimen only; furthermore, $P$ - $h$ curves from the tests on $\mathrm{CrMoV}$ have been corrected for thermal drift. 
a)

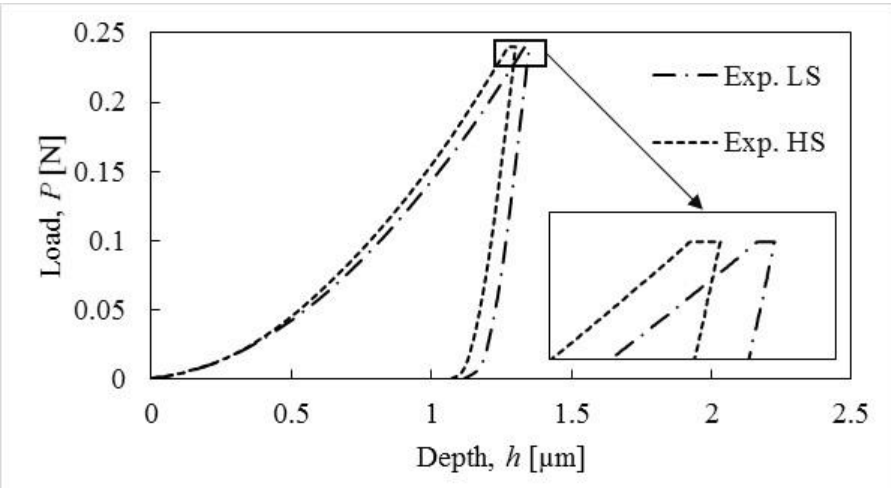

b)

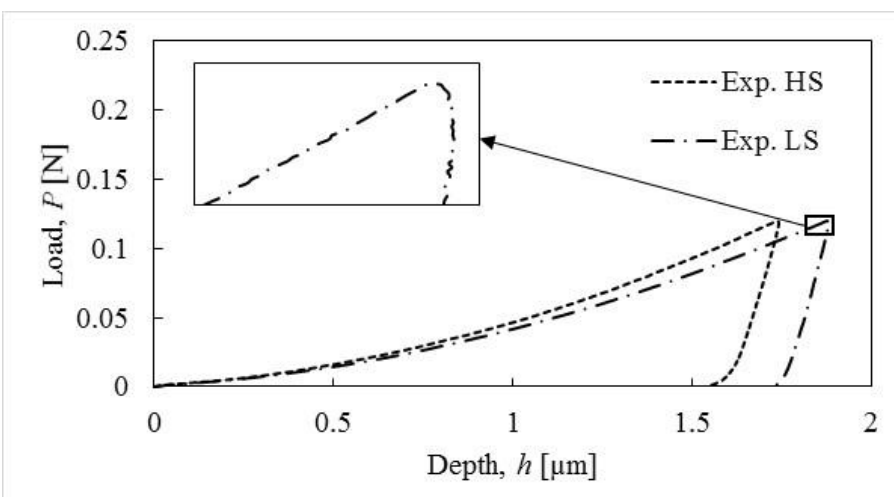

c)

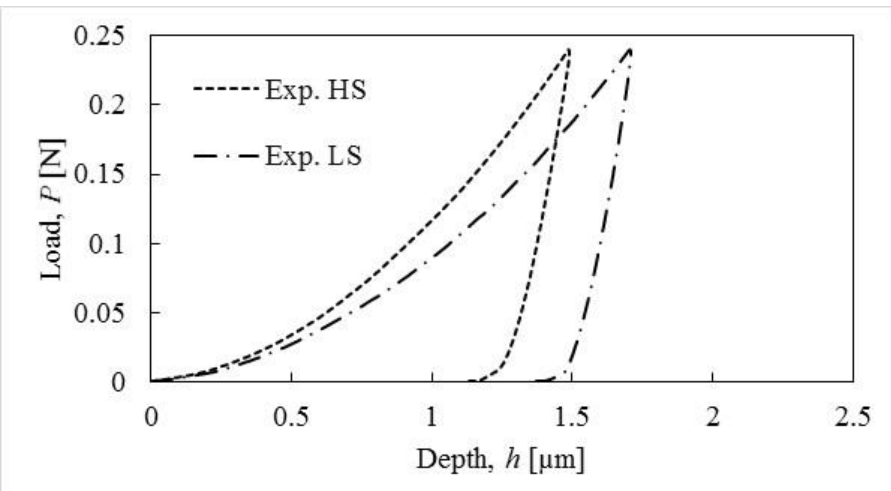

Figure 7. P-h curves selected for recovering the mechanical properties of a) CrMoV steel, b) C110 copper and c) Ti-6Al-4V.

Table 4 presents the value of maximum indentation depth as measured by both the AFM $\left(h_{0}\right)$ and depth-sensing indentation instrument $\left(h_{r}\right)$. The difference can be associated with the contribution of calibration errors in both the depth sensing indentation and AFM instruments. Due a significant difference in the residual depth $h_{0}$ in relation with $h_{r}$ measured in the Ti-6Al$4 \mathrm{~V}$ specimen, only the data above the free surface was used in the inverse analysis in order to avoid convergence issues. 
Table 4. Residual indentation depth as measured by the indentation instrument $\left(h_{r}\right)$ and AFM $\left(h_{0}\right)$.

\begin{tabular}{ccc}
\hline Specimen & $h_{0_{-} E x p}[\mu \mathrm{m}]$ & $h_{0_{-} \operatorname{Exp}} / h_{r_{-} \operatorname{Exp}}$ \\
\hline CrMoV & 1.08 & 0.97 \\
C110 & 1.57 & 1.02 \\
Ti-6Al-4V & 1.22 & 0.89 \\
\hline
\end{tabular}

For each material, the space of possible solutions for the Young's modulus and strain hardening exponent has been limited by bound constraints taking as a guide the work of Waterman and Ashby [42] and Altan et al. [43], respectively. In the spirit of Tabor [44], the stress at 8\% plastic strain of C110, CrMoV and Ti-6Al-4V, computed from the HM of the $P$ - $h$ curve that exhibited the stiffer response, was calculated as 486, 1832 and $1268 \mathrm{MPa}$, respectively; therefore, in order to allow a wider range of material properties so as to account for ISE, the optimisation model is subject to the bound constraints specified in Table 5.

Table 5. Bound constraints imposed to the optimisation procedures

\begin{tabular}{cccc}
\multicolumn{4}{c}{ of CrMoV steel, C110 copper and Ti-6Al-4V. } \\
\hline Material & $E(\mathrm{GPa})$ & $\sigma_{y}(\mathrm{MPa})$ & $n$ \\
\hline CrMoV & $150-260$ & $1000-2500$ & $0-0.25$ \\
C110 & $50-150$ & $300-600$ & $0-0.25$ \\
Ti-6Al-4V & $50-200$ & $1000-1800$ & $0-0.25$ \\
\hline
\end{tabular}

As introduced in Table 6, four sets of constitutive parameters, arbitrarily selected to cover the range of material properties delimited by the bound constraints, have been defined as the initial guess in order to assess the convergence power of the model. 
Table 6. Initial guess parameters selected to initialise the optimisations of CrMoV, Ti-6Al-4V and C110 using single- and multiple-objective functions.

\begin{tabular}{cccccc}
\hline \hline Material & Parameter & $\mathrm{R} 1$ & $\mathrm{R} 2$ & $\mathrm{R} 3$ & $\mathrm{R} 4$ \\
\hline \hline \multirow{3}{*}{ CrMoV } & $E_{0}[\mathrm{MPa}]$ & 150000 & 220000 & 250000 & 190000 \\
& $\sigma_{y 0}[\mathrm{MPa}]$ & 1400 & 2000 & 2500 & 1000 \\
& $n_{0}$ & 0.05 & 0.15 & 0.25 & 0 \\
$\mathrm{C} 110$ & $E_{0}[\mathrm{MPa}]$ & 95000 & 70000 & 80000 & 150000 \\
& $\sigma_{y 0}[\mathrm{MPa}]$ & 600 & 300 & 350 & 500 \\
& $n_{0}$ & 0.25 & 0 & 0.05 & 0.15 \\
\hline \multirow{3}{*}{ Ti-6Al-4V } & $E_{0}[\mathrm{MPa}]$ & 90000 & 200000 & 100000 & 150000 \\
& $\sigma_{y 0}[\mathrm{MPa}]$ & 1000 & 1800 & 1100 & 1500 \\
& $n_{0}$ & 0 & 0.25 & 0.05 & 0.15 \\
\hline \hline
\end{tabular}

\subsubsection{Enhancement in convergence properties attained with the MOF model}

Figure 8, Figure 9 and Figure 10 present the iteration history through the optimisations of the CrMoV steel, C110 copper and Ti6A14V materials respectively. In general, the MOF model converged faster than the SOF model.

In Figure 8, it can be seen that the MOF model converged to consistent solutions regardless of the initial guess parameters, while the SOF model showed a weaker convergence capability. In fact, for the optimisation with initial guess parameters of $\boldsymbol{x}_{\boldsymbol{0}}=[250000,2500,0.25]$ the SOF model was incapable of recovering from a local solution. Interestingly, during the first 2 iterations both the MOF and SOF passed through similar values, but during the proceeding iterations, the SOF remained trapped in the local solution for $\sigma_{y}$ and $n$. As can be noticed in Table 7, the MOF tends to converge at higher $E$ and lower $\sigma_{y}$ compared to the SOF model. The reason for this trend can be attributed to the known dependency of the pile-up/sink-in phenomenon to both the ratio of $E / \sigma_{y}$ and $n$ [2] and thus the pile-up profile is effectively adding more constraint to the model. This could also explain the capability of the MOF model to recover from the local solution previously mentioned (compare iteration $i=4$ in both Figure $8 \mathrm{a}$ and b). Overall, a less scattered set of solutions was achieved using the MOF model, compared with that of the SOF model, with a variability, measured as the relative difference between the mean value and one standard deviation, of $1.00 \%$ for $E, 1.67 \%$ for $\sigma_{y}$ and $7.80 \%$ for $n$ as reported in Table 7. In contrast, the SOF achieved solutions to $E, \sigma_{y}$ and $n$ with one 
standard deviation of up to $1.27,5.63$ and $27.94 \%$ for the corresponding parameters; therefore, the convergence of the optimisation model was enhanced by the addition of a second objective.

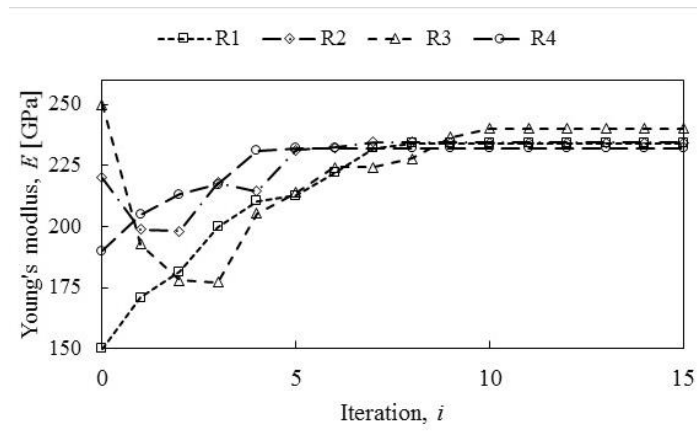

a)

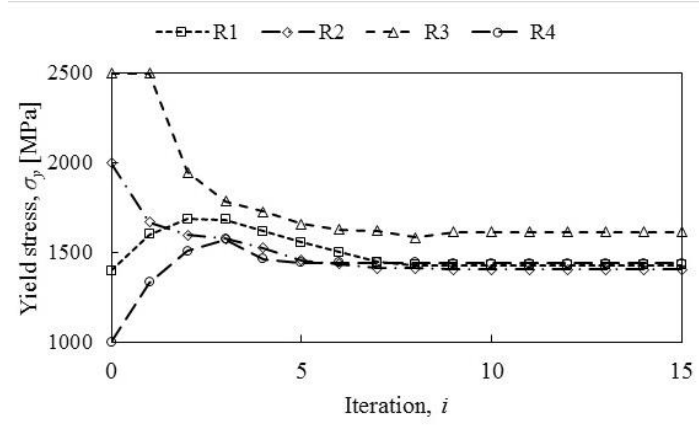

c)

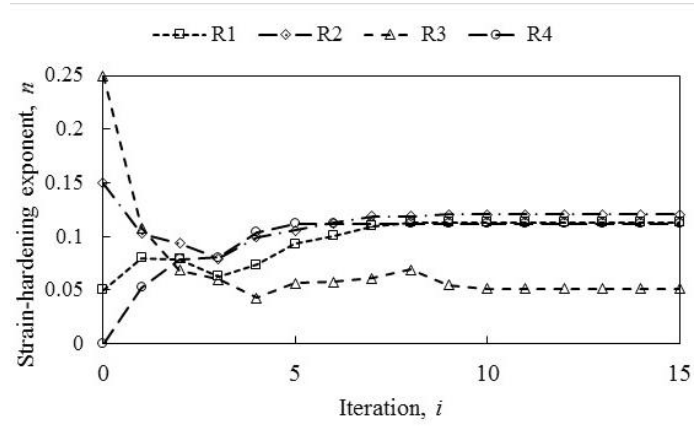

e)

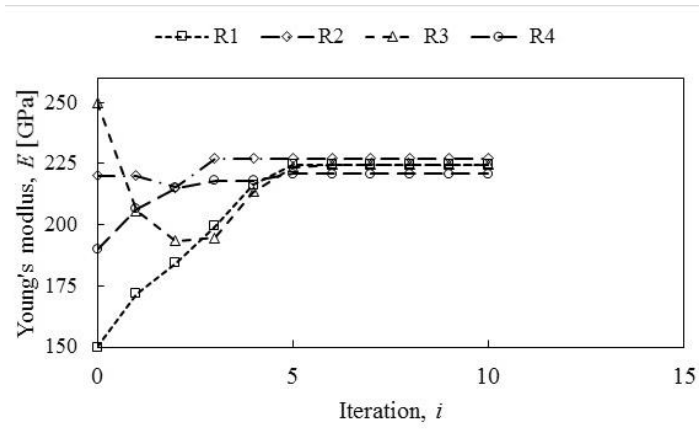

b)

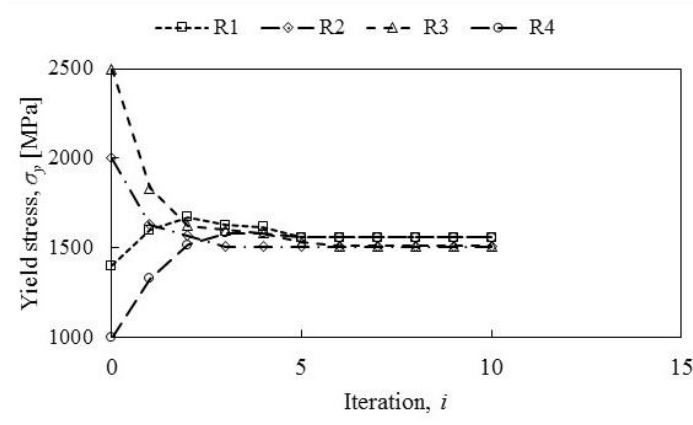

d)

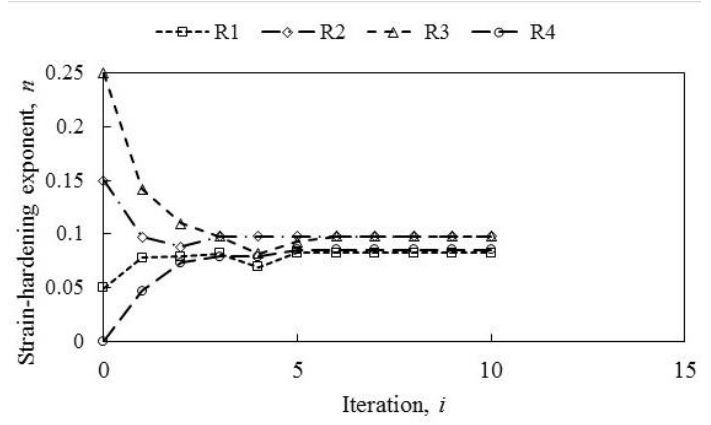

f)

Figure 8. Iteration history through the minimisation problem of a), c), e) single objective and b), d), f) multiple objectives for the determination of elastic-plastic properties of CrMoV steel. 
Table 7. Characterised properties of $\mathrm{CrMoV}$ after single- and multi-objective function optimisation.

\begin{tabular}{lcccccc}
\hline \multirow{2}{*}{ Initial guess } & \multicolumn{2}{c}{ Single-objective function } & \multicolumn{3}{c}{ Multi-objective function } \\
& $E[\mathrm{MPa}]$ & $\sigma_{y}[\mathrm{MPa}]$ & $n$ & $E[\mathrm{MPa}]$ & $\sigma_{y}[\mathrm{MPa}]$ & $n$ \\
\hline $\mathrm{R} 1$ & 233950 & 1431 & 0.1131 & 224551 & 1560 & 0.0823 \\
$\mathrm{R} 2$ & 234248 & 1407 & 0.1203 & 227019 & 1507 & 0.0977 \\
$\mathrm{R} 3$ & 240095 & 1616 & 0.0515 & 224546 & 1510 & 0.0977 \\
$\mathrm{R} 4$ & 232138 & 1441 & 0.1121 & 220753 & 1560 & 0.0851 \\
\hline Mean & 235108 & 1474 & 0.0993 & 224217 & 1534 & 0.0907 \\
Std. Dev. [\%] & 1.27 & 5.63 & 27.94 & 1.00 & 1.67 & 7.80 \\
\hline \hline
\end{tabular}

Likewise, the MOF model reached more consistent solutions to the constitutive parameters of C110 copper as observed in Figure 9a-f, presenting a superior convergence performance of the MOF over the SOF as highlighted by the reduced variability in the solution as reported in Table 8. In contrast, as presented in Table 8, the SOF model converged to dissimilar sets of material properties. Surprisingly, the iteration history throughout the MOF model (Figure 9b, $d$ and $f$ ) reveals that convergence was reached after the second iteration in the majority of the optimisation trials, despite the significant variation of at least $100 \%$ between the upper and lower parameter $\left(E, \sigma_{y}\right.$ and $\left.n\right)$ selected to initialise the optimisation. A trend similar to the optimisation history of $\mathrm{CrMoV}$ steel can be observed in Figure 9 and Table 8 with the solutions provided by the MOF model reaching a lower $E$ and higher $\sigma_{y}$ value, respectively, compared with those of the SOF. 


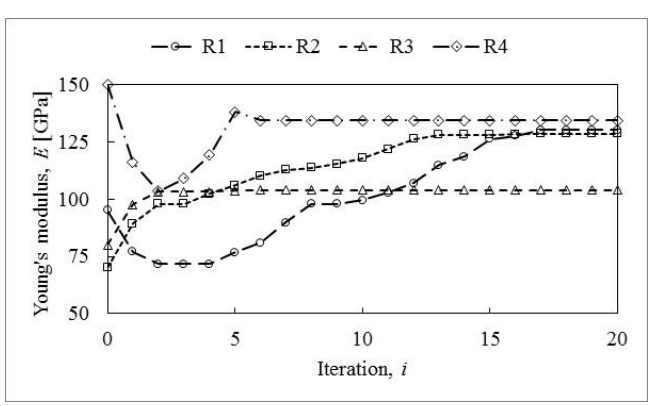

a)

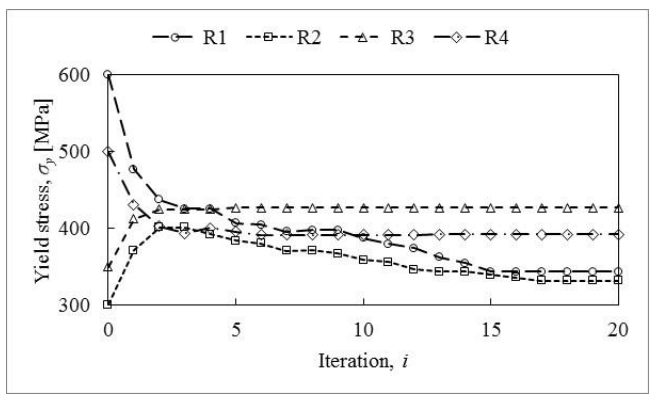

c)

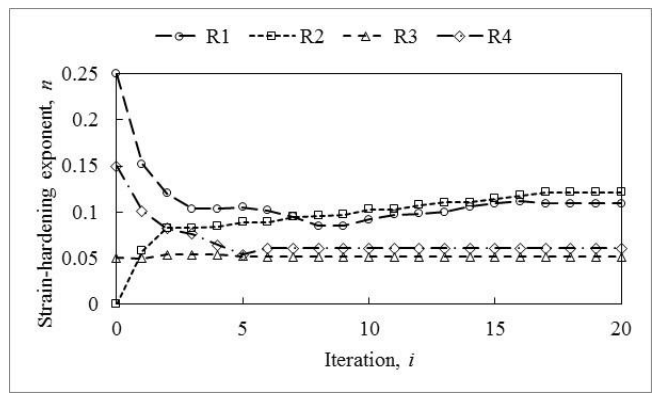

e)

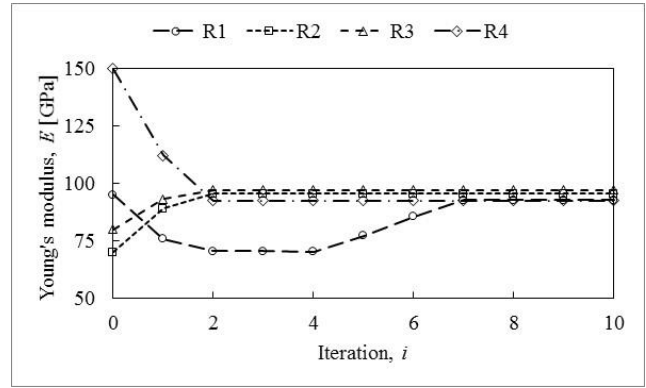

b)

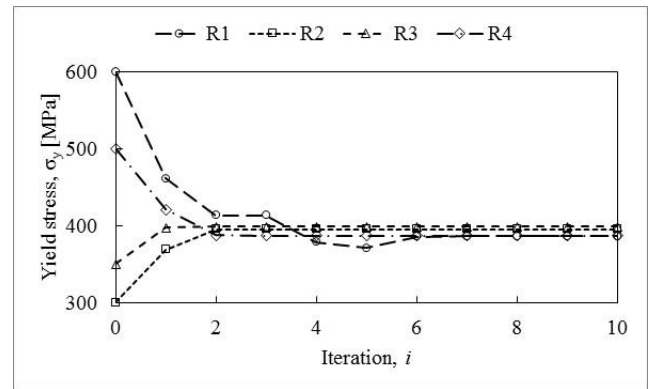

d)

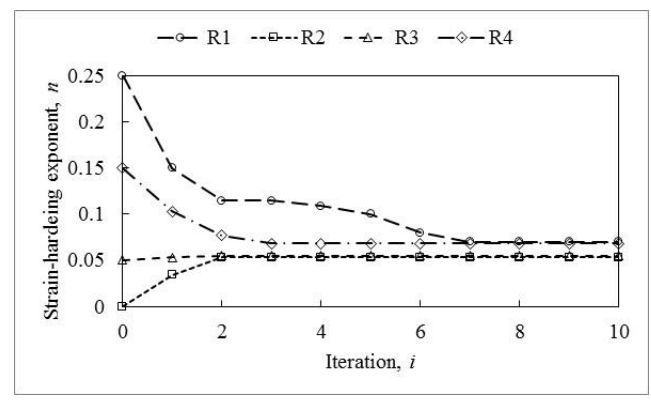

f)

Figure 9. Iteration history through the minimisation problem of a), c), e) single objective and b), d), f) multiple objectives for the determination of elastic-plastic properties of $\mathrm{C} 110$ copper.

Table 8. Characterised properties of $\mathrm{C} 110$ copper after single- and multi-objective function optimisation.

\begin{tabular}{ccccccc}
\hline \multirow{2}{*}{ Iteration } & \multicolumn{3}{c}{ Single-objective function } & \multicolumn{3}{c}{ Multi-objective function } \\
& $E[\mathrm{MPa}]$ & $\sigma_{y}[\mathrm{MPa}]$ & $n$ & $E[\mathrm{MPa}]$ & $\sigma_{y}[\mathrm{MPa}]$ & $n$ \\
\hline \hline R1 & 130109 & 343 & 0.1095 & 92610 & 386 & 0.0699 \\
$\mathrm{R} 2$ & 128474 & 332 & 0.1213 & 95511 & 395 & 0.0530 \\
$\mathrm{R} 3$ & 103843 & 427 & 0.0513 & 97147 & 398 & 0.0549 \\
R4 & 134154 & 392 & 0.0607 & 92413 & 387 & 0.0684 \\
\hline Mean & 124145 & 374 & 0.0857 & 94420 & 392 & 0.0616 \\
Std. Dev. [\%] & 9.6 & 10.2 & 35.2 & 2.1 & 1.4 & 12.5 \\
\hline \hline
\end{tabular}


For the case of Ti-6Al-4V, the indentation response is a result of the material behaviour of grains of both the $\alpha$ and $\beta$ phases and their interaction with neighbouring grains, which is beyond the capabilities of the conventional continuum plasticity approach used in the FE formulation. Error is therefore inherent in the MOF algorithm and hence, the consistency in the optimised $n$ is slightly affected as reported in Figure 10 and Table 9. Notwithstanding, the MOF model achieved a reduced variability in the converged solution for all three parameters, compared with that of the SOF model, as reported in Table 9. Furthermore, the SOF model was susceptible to converge on a local solution as was the case for the optimisation R1; as observed in Figure 10a, $\mathrm{c}$ and d, the model reached an apparent local solution for $\sigma_{y}$ and $n$ at the sixth iteration as a result of the lack of information in the $P$ - $h$ curve to describe the plastic behaviour of the indented material. It is to be noted through the iteration history followed by the SOF optimisation, that the lower bound constraint imposed on the model $\left(\sigma_{y}>1000 \mathrm{MPa}\right)$ prevented a further reduction in the value of $\sigma_{y}$ as shown in Figure 10c, which otherwise would result in a larger error. 


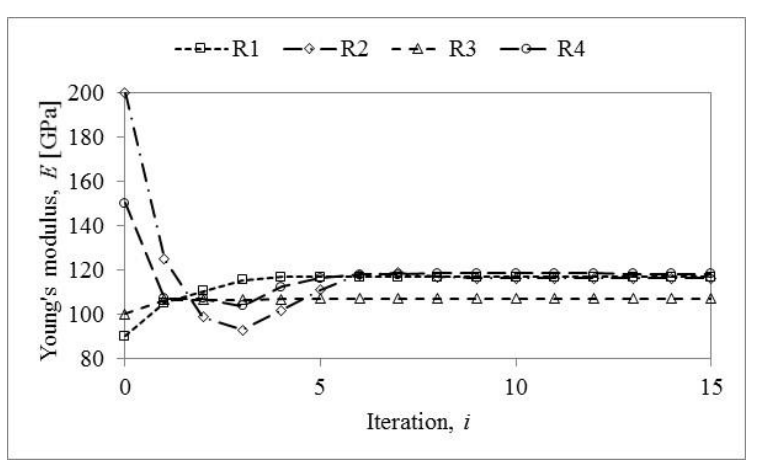

a)

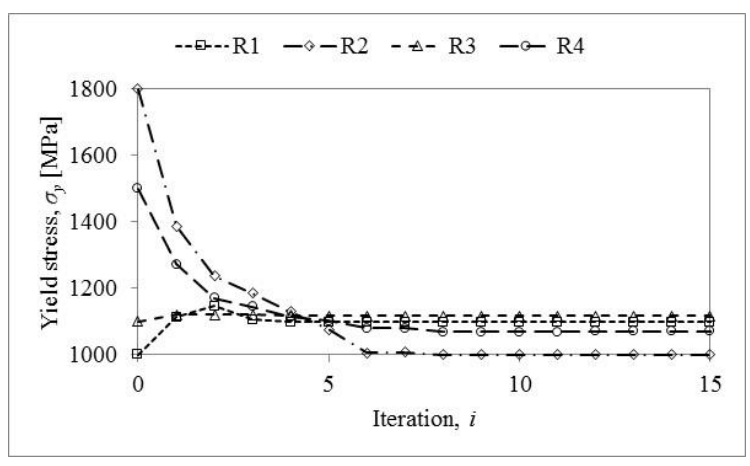

c)

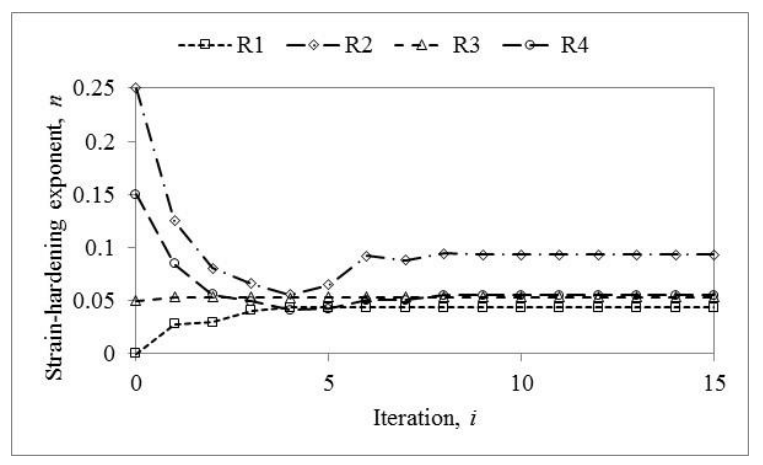

e)

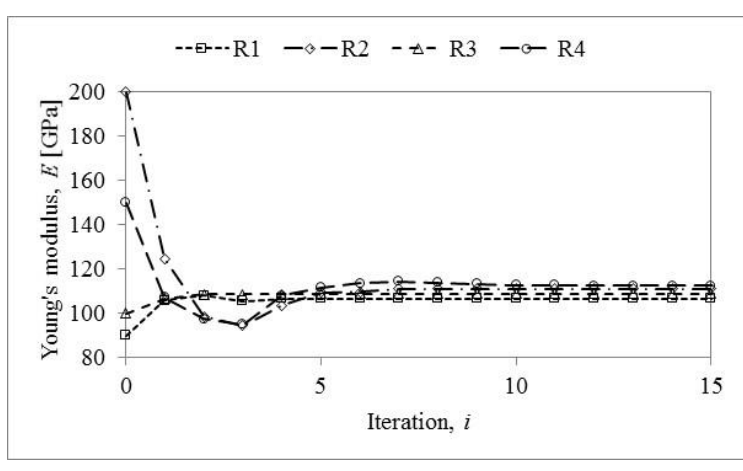

b)

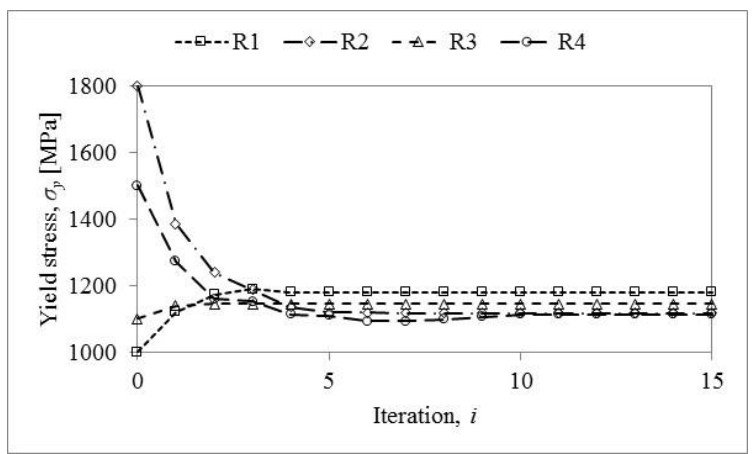

d)

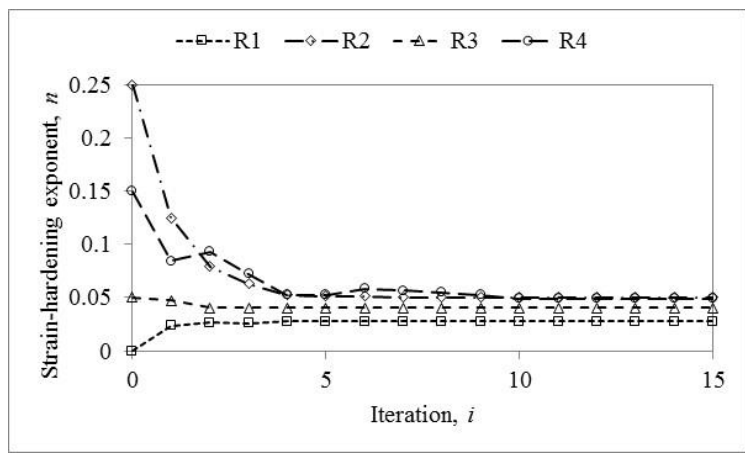

f)

Figure 10. Iteration history through the minimization problem of a), c), e) single objective and b), d), f) multiple objectives for the determination of elastic-plastic properties of Ti-6Al-4V. 
Table 9. Characterised properties of Ti-6Al-4V after single- and multi-objective function optimisation.

\begin{tabular}{lcccccc}
\hline \hline \multirow{2}{*}{ Initial guess } & \multicolumn{3}{c}{ Single-objective function } & \multicolumn{3}{c}{ Multi-objective function } \\
& $E[\mathrm{MPa}]$ & $\sigma_{y}[\mathrm{MPa}]$ & $n$ & $E[\mathrm{GPa}]$ & $\sigma_{y}[\mathrm{MPa}]$ & $n$ \\
\hline \hline $\mathrm{R} 1$ & 116568 & 1099 & 0.0432 & 106468 & 1179 & 0.0276 \\
$\mathrm{R} 2$ & 116083 & 1000 & 0.0935 & 110912 & 1117 & 0.0504 \\
$\mathrm{R} 3$ & 107029 & 1117 & 0.0534 & 108822 & 1144 & 0.0407 \\
$\mathrm{R} 4$ & 118139 & 1070 & 0.0552 & 112476 & 1113 & 0.0490 \\
\hline Mean & 114455 & 1071 & 0.0613 & 109669 & 1138 & 0.0419 \\
Std. Dev. [\%] & 3.80 & 4.14 & 31.14 & 2.06 & 2.31 & 21.70 \\
\hline \hline
\end{tabular}

\subsubsection{Mechanical response to indentation as predicted by the optimisation model}

The trust-region-reflective algorithm is a highly regarded method for its strong fitting capabilities [35] and thus, as evidenced in Figure 11, the recovered properties using both the SOF and MOF model led to remarkably consistent $P$ - $h$ curves, in very good agreement with the corresponding experimental curves. Therefore, for clarity, Figure 11 compares the experimental $P$ - $h$ curve with that of the indentation response of only one of the optimised sets of material properties provided by the SOF and MOF model. The maximum indentation depth $\left(h_{\max }\right)$ measured by the indentation instrument in specimens of CrMoV steel, C110 copper and Ti-6Al-4V was predicted by the SOF model with a 2.5, 2.7 and $1.4 \%$ error, respectively; the MOF model slightly reduced the corresponding errors to 2.4, 1.5 and 1.4\%. Similarly, the depth after the load has completely removed $\left(h_{r}\right)$ in specimens of CrMoV steel, C110 copper and Ti$6 \mathrm{Al}-4 \mathrm{~V}$, respectively, was predicted with errors of 5.6, 6.6 and $8.4 \%$ by the SOF and 5.0, 11.0 and $7.4 \%$ by the MOF. The main concern with the SOF model is that the nearly indistinguishable $P$ - $h$ curves represent the indentation response of a variety of material properties as reported in Table 7 to Table 9, i.e. the solution was not unique. 
a)

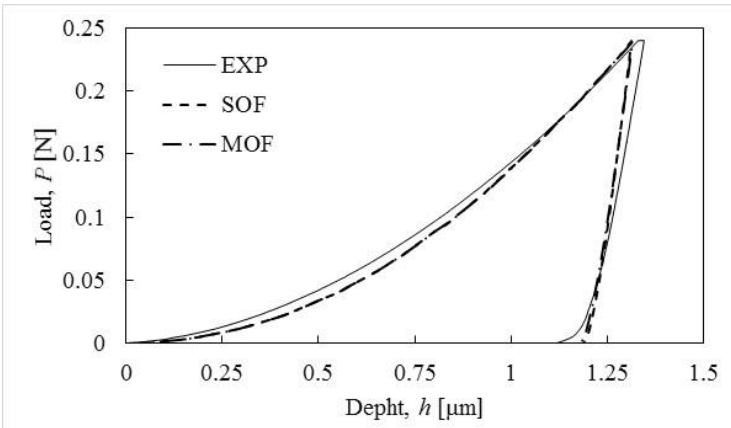

b)

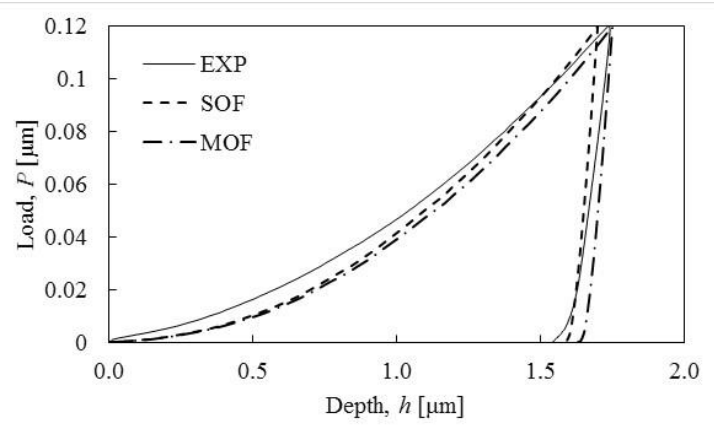

c)

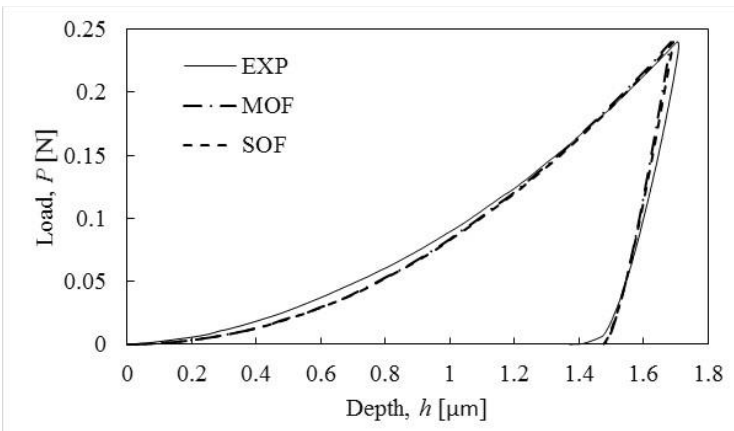

Figure 11. Fitting of optimised curve to experimental curve via the single- and multiple- objective function optimisation model for the corresponding material: a) $\mathrm{CrMoV}$ steel, b) C110 copper and c) Ti-6Al-4V.

The MOF optimisation model proved to be a step forward to the characterisation of the nearsurface properties as, in contrast to the $P$ - $h$ curve, the residual imprint is strongly linked to the plastic behaviour of the indented material; therefore, the physics of the indentation problem was better represented as can be demonstrated by studying the volume of displaced material predicted by the MOF model, compared with experimental measurements taken via AFM (Figure 12). After convergence, the FE model approximated the area of the residual imprint extracted from the AFM scans for CrMoV steel, C110 copper and Ti-6Al-4V with an error of $5.1,10.8$ and 12.4\%, respectively, as reported in Table 10. Moreover, the convex shape of the sides of the triangular area of indentation in $\mathrm{CrMoV}$ and $\mathrm{Ti}-6 \mathrm{Al}-4 \mathrm{~V}$, resulting from the recovery of displacements upon unloading, was very well predicted by the FE model, as can be seen by comparing Figure $12 \mathrm{a}$ with $\mathrm{b}$ and Figure $12 \mathrm{e}$ with $\mathrm{f}$. In addition, the straight sides of the residual 
imprint predicted from the recovered properties of C110 copper (Figure 12d) were consistent with the experimental measurements (Figure 12c).

Table 10. Imprint area of indentation measured via AFM $(A)$ compared with predicted area by the FE model after convergence

\begin{tabular}{cccc}
\multicolumn{4}{c}{$\left(A_{F E}\right)}$. \\
\hline Material & $A\left[\mu \mathrm{m}^{2}\right]$ & $A_{F E}\left[\mu \mathrm{m}^{2}\right]$ & $\Delta A / A[\%]$ \\
\hline CrMoV & 39.0 & 37.0 & 5.1 \\
C110 & 79.9 & 71.3 & 10.8 \\
Ti-6Al-4V & 46.1 & 51.8 & 12.4 \\
\hline
\end{tabular}

Circles A, B and C were drawn on the displacement contour plots produced by the optimised FE model (Figure 12b and d) and are intended to characterise the three main regions where material displaced plastically during indentation. Radii A, B and C are measured, respectively, from the centre of indentation to the point of maximum pile up, the intersection of the imprint edges and the far-field where the piled-up material meets the original indentation surface. In order to prove the strong capabilities of the MOF model to represent the elastic-plastic deformation history experienced by the indented material, the size of regions $\mathrm{A}, \mathrm{B}$ and $\mathrm{C}$ has been superimposed on the corresponding top view provided by the AFM (Figure 12a and c). Referring to Figure 12a and b, both the AFM measurement and FE prediction showed that the volume of plastically displaced material was confined to a region adjacent to the indentermaterial interface, identified as region $\mathrm{C}$, and reached a maximum pile-up height within region A. Accordingly, the pile-up height decreased away from the indenter centreline and towards the intersections of the indenter edges, i.e. the corners of the triangle. Also, in agreement with experimental measurements, the FE model provided evidence that in the neighbourhood of the corners of the triangle, the material does not show a dominant plastic flow behaviour, i.e. piling-up or sinking-in. This behaviour was consistently delimited by region B in both the real and predicted residual imprint. Examining the predicted plastic flow of material in Figure 12d, it was observed that $\mathrm{C} 110$ copper piled-up predominantly towards the bisector of the side of the triangular impression within region A. Moving away from the centreline of the indenter, the height decreased until the free surface was reached beyond region $\mathrm{C}$. It was also noticeable a steeper decrease in height, compared with the imprint in $\mathrm{CrMoV}$, as the corners of the triangle are approached. These trends and the regions where they occurred were highly consistent with the experimentally measured residual imprint as can be demonstrated by tracing the drawings of regions $\mathrm{A}, \mathrm{B}$ and $\mathrm{C}$ of Figure 12d on Figure 12c. In contrast, it was evident that the complex 
plastic deformation behaviour of the dual-phase microstructure of Ti-6Al-4V was beyond the capabilities of an FE model based on the continuum mechanics approach; however, the height measurements in the direction in which the pile-up profile was extracted (direction $e$ in Figure 12), was represented accordingly by the FE model as discussed below.

\section{AFM measurements}

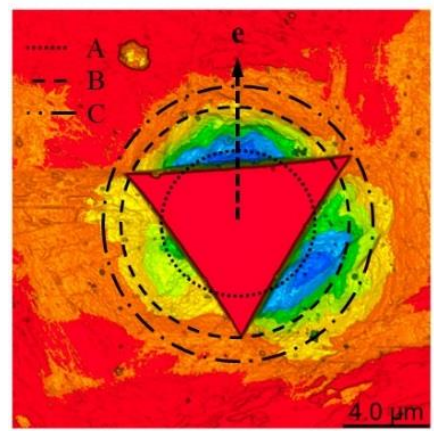

a)

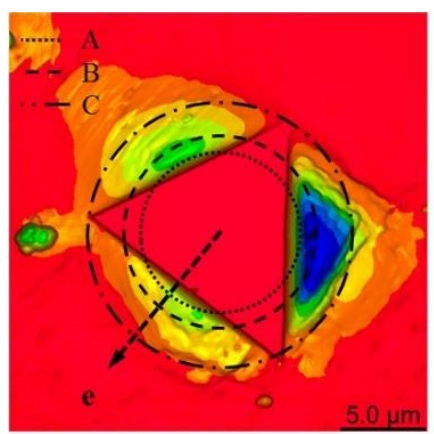

c)

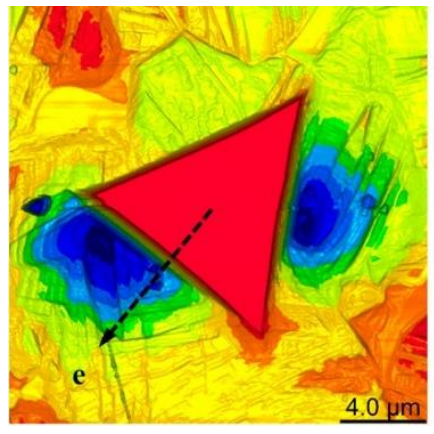

e)

\section{Optimised FE prediction}
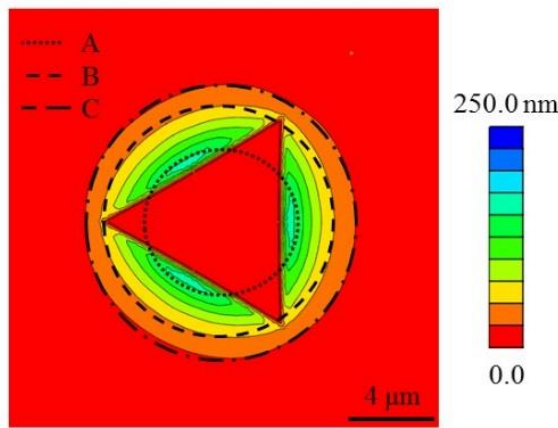

b)
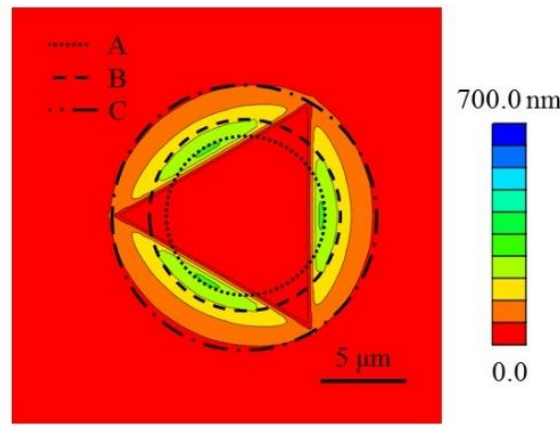

d)

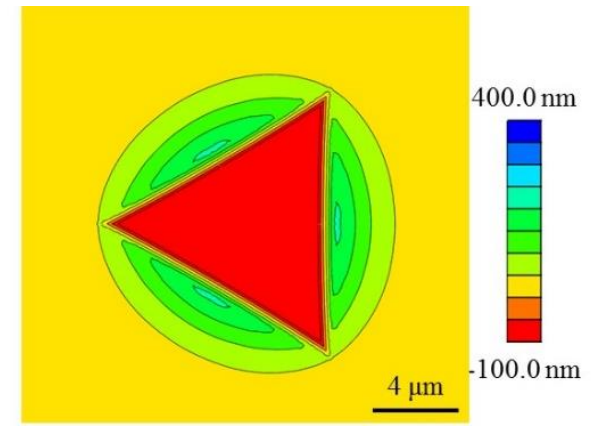

f)

Figure 12. Top views of the residual imprints on specimens of a) $\mathrm{CrMoV}$ steel, b) C110 copper and c) Ti-6Al-4V. The left column presents the height measurements provided by the AFM and the right column the FE predictions using the optimised properties. 
A more detailed assessment was conducted by studying the pile-up profiles extracted from the height measurements provided by the AFM as presented in Figure 13. To facilitate interpretation, Table 11 includes the quantitative information concerning the fitting of the SOF and MOF model to the experimental residual profile. Figure 13a, c and e show that despite the very consistent $P$ - $h$ curves, which are governed mostly by the $E$ and $\sigma_{y}$ parameters, the SOF model lacks the capability to recognise the significantly different behaviour of the plasticised material beneath the indenter, which is strongly linked to the parameter $n$. As a matter of fact, the material properties determined by the SOF model as presented in Table 7 to Table 9 are, correspondingly, 'siblings' to one another, i.e. their indentation response is nearly identical regardless of the dissimilar material properties that define their constitutive behaviour. For instance, the coefficient of variation between the $P$ - $h$ curves R2 and R3 shown in Figure 13c, which represent the indentation response of the material properties identified in Table 8, was less than $1 \%$ regardless of the significant deviation between the constitutive parameters of R2 in relation to R3, i.e. $-23.7 \%$ in $E$, $-22.2 \%$ in $\sigma_{y}$ and $136 \%$ for $n$. Notwithstanding, the maximum pile-up height differed by more than $30 \%$; therefore, the risk of the non-uniqueness issue of the inverse analysis of indentation poses a threat to the reliability of the inverse analysis purely based on $P$ - $h$ curves. Conversely, Figure $13 \mathrm{~b}, \mathrm{~d}$ and $\mathrm{f}$ show the consistency achieved in the prediction of the plastic response of the indented material with the MOF model. Notwithstanding, comparing Figure 13e and $\mathrm{f}$, the MOF model attempted to provide a best fit between experimental and predicted data and hence the recovered material properties yielded to a mean error in $h_{\text {peak }}=3.9 \%$, which was lower than the error of $7.6 \%$ incurred by the SOF model. Surprisingly, although the information beneath the free surface was not included in the optimisation of Ti-6Al-4V, the predicted $h_{0}$ by the SOF and MOF model closely approached the residual depth measured by the indentation instrument $\left(h_{r}\right)$ to a relative deviation of less than $7.9 \%$ and $6.8 \%$ respectively. Therefore, rather than a failure of the MOF model, the variation in the optimised $n$ for Ti- $6 \mathrm{Al}-4 \mathrm{~V}$ is attributable to the incompatibility between the macroscale approximation included in the FE model and the microscale plasticity behaviour of polycrystalline materials. 


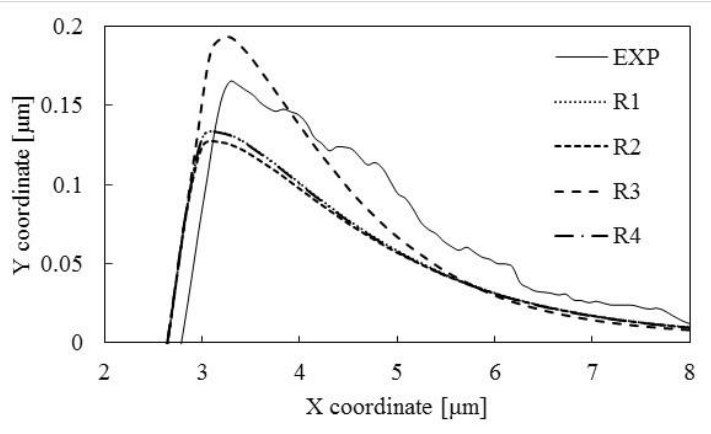

a)

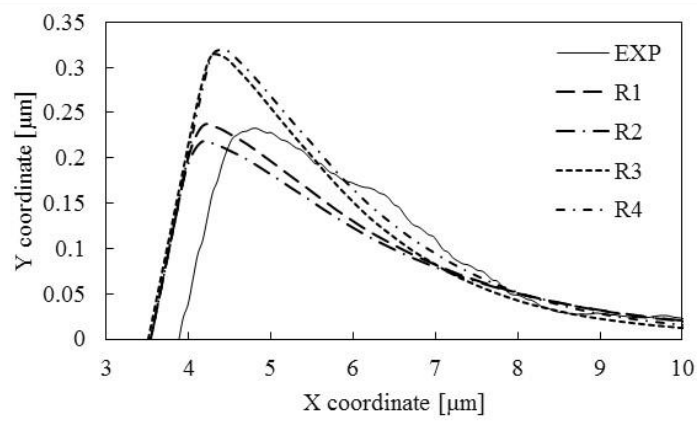

c)

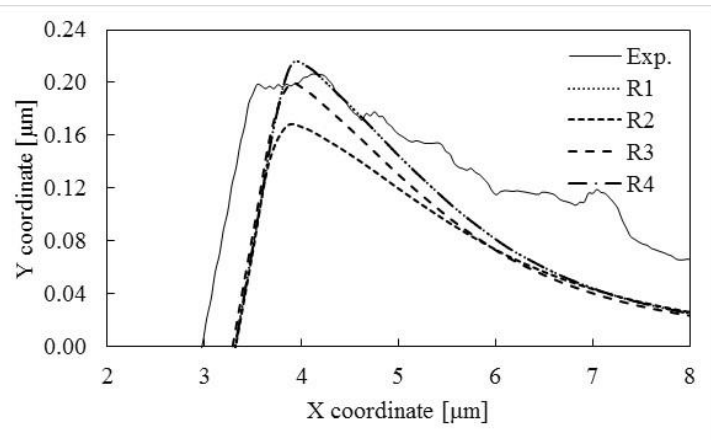

e)

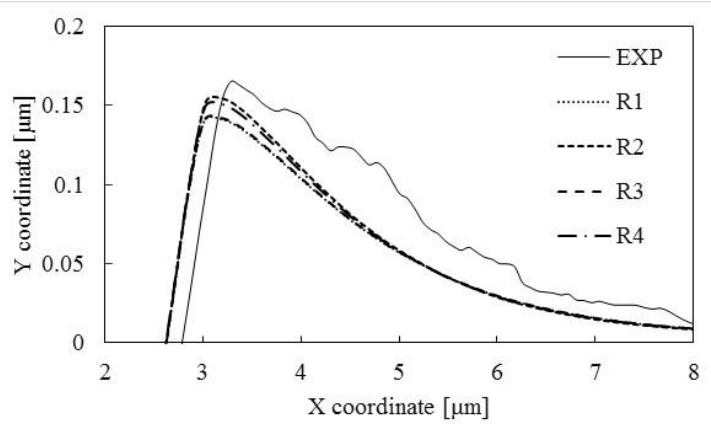

b)

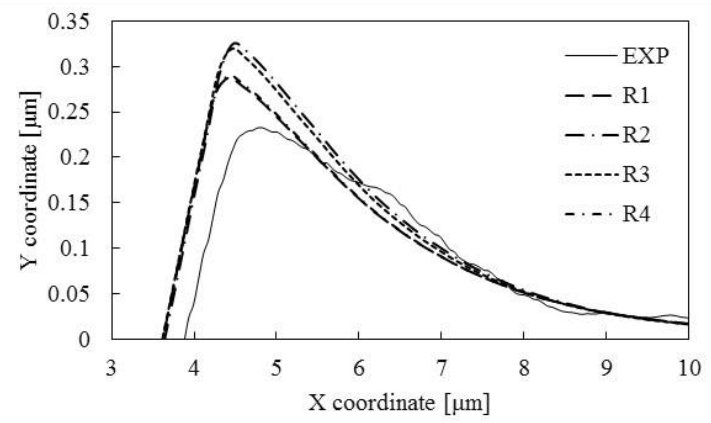

d)

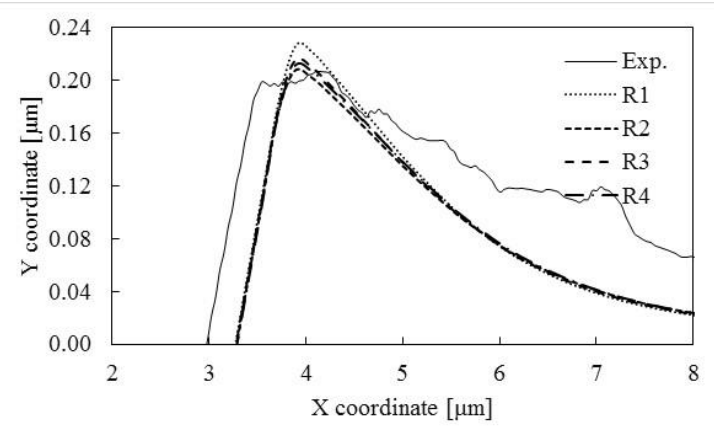

f)

Figure 13. Experimental pile-up profile in indentations of a), b) $\mathrm{CrMoV}$ steel, c), d), C110 copper and e), f) Ti-6Al-4V fitted by the single- (left) and multiple- (right) objective function optimisation model

Table 11. Mean values of the peak pile-up height $\left(h_{\text {peak }}\right)$ and residual depth $\left(h_{0}\right)$ as predicted by the SOF and MOF.

\begin{tabular}{ccccc}
\hline & \multicolumn{2}{c}{ Single-objective function } & \multicolumn{2}{c}{ Multi-objective function } \\
\hline Material & $\Delta h_{\text {peak }} / h_{\text {peak_Exp }}$ & $\Delta h_{0} / h_{0_{-} E x p}$ & $\Delta h_{\text {peak }} / h_{\text {peak_Exp }}$ & $\Delta h_{0} / h_{0 \_ \text {Exp }}$ \\
CrMoV & 19.9 & 8.7 & 11.0 & 8.1 \\
Ti-6Al-4V & 7.6 & $7.9^{(1)}$ & 3.9 & $6.8^{(1)}$ \\
C110 & 19.7 & 0.7 & 31.3 & 3.6 \\
\hline
\end{tabular}

(1) $\Delta h_{0} / h_{r_{-} E x p}$ 


\section{Discussion}

In order to assess the variation in derived properties using the pile-up data, additional runs were performed using the other two pile-up profiles extracted from each indentation. It was observed that the largest difference among optimised properties for all three materials was seen in the strain-hardening exponent, this can be explained due to the known relationship between the strain-hardening and the pile-up of material during indentation [2]. For all three materials, the greater the pile-up above the free surface, the lower the recovered strain-hardening exponent. The recovered Young's modulus also showed considerable sensitivity to the direction of the pile-up profile, with coefficients of variation of 6.0, 16.9 and $32.1 \%$ for $\mathrm{CrMoV}, \mathrm{C} 110$ and Ti$6 \mathrm{Al}-4 \mathrm{~V}$, respectively. On the other hand, the optimised value of yield stress was found to be very consistent, regardless of the direction of the pile-up profile with a coefficient of variation of 3.1, 4.4 and $4.8 \%$ for $\mathrm{CrMoV}, \mathrm{C} 110$ and Ti-6Al-4V, respectively. In order to account for the uncertainty arising from the effect of the direction of the pile-up profile on the recovered properties, an additional optimisation was carried out for each material using the average of the three pile-up profile directions and the recovered properties compared with those obtained from uniaxial test data, as presented in Figure 14. It can be seen that the stress-strain relationships of the material at the micro- and macro-scale differ, which can be attributed to: (i) the macroscale properties measured by the uniaxial tensile test describe the average of the mechanical response of the microstructure to external stimuli, i.e. the bulk properties; and (ii) a uniaxial stress-strain curve represents an incomplete description of plastic deformation as it reduces a six-dimensional yield surface and its change upon loading to a one-dimensional (scalar) yield curve [45]. On the other hand, the optimised properties were recovered from the indentation response of the microstructure, which includes multiple phenomena neglected at macroscale, e.g. the heterogeneity of crystalline matter, the orientation dependence of the activation of the crystallographic deformation mechanisms, the extent of the mis-orientation between grains, the anisotropy of crystals and the strain gradient plasticity at low loads.

The significant difference in the predicted properties for the case of $\mathrm{C} 110$ copper, as reported in Table 12, can, therefore, be attributed in part to the lack of a length parameter (required to account for ISE) in the continuum mechanics approach used in FE modelling. As the grain size in relation to indentation size is smaller in $\mathrm{CrMoV}$ steel and Ti-6Al-4V, microstructural effects are diminished and consequently a better prediction was achieved. Notwithstanding, the difference between the micro- and macro-scale Young's modulus measured on Ti-6Al-4V can 
be also attributed to the interaction between the $\alpha$ - and $\beta$-grains with the Berkovich tip during indentation. On the other hand, a very good agreement between the predicted and measured elastic-plastic properties can be noted in Table 12 for the case of $\mathrm{CrMoV}$, where the ratio of grain size to indentation size is significantly below unity.

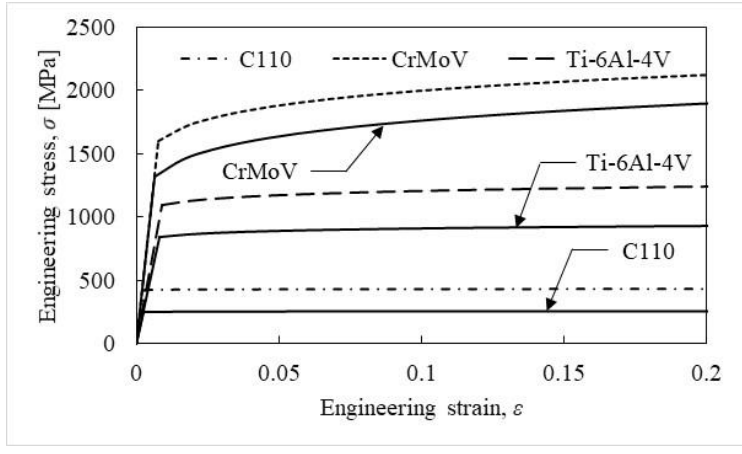

Figure 14. Constitutive relationship as determined by the multiple-objective function optimisation model (dashed lines). The engineering stressengineering strain extracted from the tensile test has been superimposed (solid lines).

Table 12. Constitutive parameters as determined by the uniaxial tensile test and inverse analysis of depth-sensing indentation data via the MOF model using the average of the pile-up profiles.

\begin{tabular}{ccccccc}
\hline \multirow{2}{*}{ Param. } & \multicolumn{2}{c}{ CrMoV } & \multicolumn{2}{c}{ C110 } & \multicolumn{2}{c}{ Ti-6Al-4V } \\
& Uniaxial & MOF & Uniaxial & MOF & Uniaxial & MOF \\
\hline$E[\mathrm{MPa}]$ & 204233 & 207679 & 99543 & 136072 & 103116 & 120966 \\
$\sigma_{y}[\mathrm{MPa}]$ & 1325 & 1600 & 249 & 428 & 839 & 1091 \\
$n$ & 0.1055 & 0.0865 & 0.0090 & 0.0035 & 0.0315 & 0.0412 \\
\hline
\end{tabular}

Additionally, the fit of a model including the pile-up profile is highly sensitive to the mechanism of plastic deformation of the microstructure. Tempered martensite grains are relatively fine $(2-3 \mu \mathrm{m})$ compared to the area of indentation reached at $P_{\max }=0.24 \mathrm{~N}, A=39$ $\mu \mathrm{m}^{2}$ as reported in Table 10, and hence the plastic deformation approximates, to some extent, that of a continuum homogeneous material; the result was a well-predicted pile-up profile (Figure 13b) with a mean error for the value of the peak pile-up height $\left(h_{\text {peak }}\right)$ of less than $11 \%$ as included in Table 11 . In contrast, the mean $h_{\text {peak }}$ predicted by the SOF deviated by up to $20 \%$ as illustrated in Figure 13a. Furthermore, the residual depth, $h_{0}$, measured in CrMoV steel was better predicted by the MOF as detailed in Table 11. The significantly coarser grains of C110 copper, which reach sizes of up to $100 \mu \mathrm{m}$, mean that indentations were likely to fall within a 
single grain as $A=79.9 \mu \mathrm{m}^{2}$ at $P_{\max }=0.12 \mathrm{~N}$. Therefore, the largest error in $h_{\text {peak }}$ and $h_{0}$ for the case of C110 copper reported in Table 11 and shown in Figure 13d was not surprising as the continuum mechanics approach used was unsuitable to represent the anisotropic behaviour of single crystals of copper. Lastly, grains of Ti-6Al-4V were not only of an equivalent size to the indented area, i.e. an $\alpha$-grain size of 20-30 $\mu \mathrm{m}$ and $A \sim 46.1 \mu \mathrm{m}^{2}$ at $P_{\max }=0.24 \mathrm{~N}$ (Table 10), but the changing material properties from grain to grain resulted in a highly distorted pile-up profile as observed in Figure 12e, which is understood by the optimisation algorithm as error in the form of noise and outliers.

A load-time sequence in experimental depth-sensing indentation test is typically designed to assess the repeatability of the test in a specific material and to avoid capturing anything other than elastic displacements during the (final) unloading stage [20]. It is common practice to include hold periods, e.g. at maximum load $\left(P_{\max }\right)$ to ensure stable material response before unloading. As can be seen in Figure 7a, time-dependent deformation was recorded by the indentation instrument over the dwell period defined at $P_{\max }$; however, in the absence of a timedependent parameter in the material model, the FE simulation will be incapable of resolving the displacements taking place during the load holding periods for the indentation experiment in $\mathrm{CrMoV}$. In contrast, not including a dwell period in the indentation experiment, or a very short hold period succeeded by a slow unloading rate, may result in an initial increase of indentation depth upon unloading due to creep [46] as illustrated in Figure 7b. The foregoing presents a further challenge to the researcher as a critical decision shall be made to avoid the discrepancy between the continuum mechanics solution and the experimental $P$ - $h$ curve results in a detriment to the optimisation procedure.

\section{Conclusions}

The strong dependency of the residual imprint left by the indenter to the plastic behaviour of the indented material was exploited to complement the information provided by the $P$ - $h$ curve and so address the non-uniqueness issue of the inverse analysis of indentation. The superior performance of the proposed MOF optimisation model, compared with a single-objective function model, was highlighted by its capability to distinguish between materials showing similar indentation responses, referred to in the literature as 'mystical' materials. While the single-objective function model was trapped on a local solution, in excess of 5.2, 38.9 and $66.7 \%$ away from the (global) target $E, \sigma_{\mathrm{y}}$ and $n$ respectively, the multi-objective function 
optimisation converged to the target properties within an error of less than $0.15 \%$ in all three parameters.

The second objective introduced in the multi-objective function optimisation model proposed in this study, provided valuable information concerning the plastic behaviour of the indented material and thus the robustness of the optimisation model was seen to be enhanced. The model provided very consistent results and proved to be capable of recovering from an apparent local solution. Furthermore, the complementary constraint added by the second objective was directly reflected in the capability of the model to distinguish between 'sibling' materials and thus the MOF model effectively addressed the non-uniqueness issue of the inverse analysis of indentation. Overall, the MOF model resulted in a faster convergence and in a reduced variability in the solution. A great fitting power provided by the trust-region algorithm resulted in experimental $P$ - $h$ curves extracted from all three materials fitted by the set of material properties to within an error of less than $2.4 \%$ and $8.4 \%$ the maximum $\left(h_{\max }\right)$ and residual $\left(h_{r}\right)$ depth, respectively.

Of great interest was the remarkably well predicted topography of indentation by the MOF model provided that grain sizes are small enough in relation with the area covered by the indenter at full load. Both the shape of the edges and the area of the triangular residual imprint were in very good agreement with experimental data. The predicted indentation area deviated 5.1, 10.8 and $12.4 \%$ from the area measurements taken in indentations of CrMoV steel, C110 copper and Ti-6Al-4V, respectively. The validity of the predictions of the plastic flow of material beneath the indenter was supported by the strong consistency achieved by the MOF model with the AFM measurements. The error between the experimental and predicted maximum pile-up height $\left(h_{\text {peak }}\right)$ was an average of $11 \%$ for indentations in CrMoV steel and $6.8 \%$ for Ti-6Al-4V. The variation in the pile-up profile predicted for $\mathrm{C} 110$ was attributed to the crystalline anisotropy of copper. Therefore, further developments are encouraged to include a more sophisticated crystal plasticity FE model in order provide a better approximation to the crystallographic deformation beneath the indenter.

Further conclusions can be drawn from the outcomes of this study concerned with the inverse analysis of experimental data by means of an optimisation procedure coupled with a conventional continuum mechanics FE model: 
- A single loading and unloading sequence is preferred for the optimisation procedure, i.e. without load-holding periods, so as to allow the comparison with the timeindependent solution provided by the FE model. The shortcoming is the risk of capturing significant displacements due to plastic recovery in the experimental $P$ - $h$ curves and consequently the optimisation model finding difficulties with fitting the experimental data. Furthermore, the dwell period at $P_{\max }$ results in an intrinsic error in the model due to the mismatch with the load-independent FE solution. Furthermore, it is recommended to leave the system over night to thermally stabilise to reduce thermal drift effects during measurements as typical FE models assume isothermal conditions.

- It is recommended to consider the possible challenges a significant time-dependent deformation may pose to the inverse analysis coupled with an FE model not provided with a time-dependent material model. Therefore, it is ideal to conduct a reference indentation experiment with a load-time sequence, i.e. dwell period and thermal drift, in order to establish the degree of error it may introduce to the optimisation model.

- Attempting to recover the mechanical properties of a material using a significantly deviated residual depth $h_{0}$ in relation with $h_{r}$ may result in convergence issues. However, it was observed that satisfactory results can be obtained by including only the above surface topography of the residual imprint.

\section{Acknowledgements}

The authors acknowledge the funding support (Grant no. 216575) from the National Council for Science and Technology (CONACyT) of Mexico.

\section{References}

1. Sneddon, I.N., The relation between load and penetration in the axisymmetric Boussinesq problem for a punch of arbitrary profile. International Journal of Engineering Science, 1965. 3(1): p. 47-57.

2. Fischer-Cripps, A.C., Nanoindentation. Mechanical Engineering Series. 2004, New York: Springer

3. Bolshakov A., P., G.m., Influences of pileup on the measurement of mechanical properties by load and depth sensing indentation techniques. Journal of Materials Research, 1998. 13(4): p. 1049-1058.

4. N'Jock, M.Y., Chicot, D., Ndjaka, J.M., Lesage, J., Decoopman, X., Roudet, F., Mejias, A., A criterion to identify sinking-in and piling-up in indentation materials. International Journal of Mechanical Sciences, 2015. 90: p. 145-150.

5. Loubet, J.L., Bauer, M.,Tonck, A., Bec, S., Gauthier, B. Manuel, Mechanical properties and deformation behaviour of materials having ultra-fine microstructures. NATO ASI Series. 1993.

6. Bhattacharya, A.K., Nix, W.D., Finite element simulation of indentation experiments. International Journal of Solids and Structures, 1988. 24(9): p. 881-891. 
7. Laursen, T.A., Simo, J.C., A study of the mechanics of microindentation using finite elements. Journal of Materials Research, 1992. 7(3): p. 618-626.

8. Giannakopoulos, A.E., Larsson, P.-L., Vestergaard, R. , Analysis of Vickers indentation. International Journal of Solids and Structures, 1994. 31: p. 2679-2708.

9. Doerner, M.F., Nix, W. D., A method for interpreting the data from depth-sensing indentation instruments. Journal of Materials Research, 1986. 1: p. 601 - 609.

10. Oliver, W.C., Pharr, G.M., An improved technique for determining hardness and elastic modulus using load and displacement sensing indentation experiments. Journal of Materials Research, 1992. 7(6): p. 1564-1583.

11. Larsson, P.-L., Giannakopoulos, A. E., Söderlund E., Rowcliffe, D. J., Vestergaard, R., Analysis of berkovich indentation. International Journal of Solids and Structures, 1996. 33(2): p. 221-248.

12. Giannakopoulos, A.E., Suresh, S., Determination of elastoplastic properties by instrumented sharp indentation. Scripta Materialia, 1999. 40(10): p. 1191-1198.

13. Venkatesh, T.A., Van Vliet, K. J., Giannakopoulos, A. E., Suresh, S., Determination of elasto-plastic properties by instrumented sharp indentation: guidelines for property extraction. Scripta Materialia, 2000. 42: p. 833-839.

14. Barenblatt, G.I., Scaling, Self-similarity, and Intermediate Asymptotics. 1996, Cambridge: Cambridge University Press.

15. Cheng, Y., Cheng, C., Scaling approach to conical indentation in elastic-plastic solids with work hardening. Journal of Applied Physics, 1998. 84: p. 1284-1291.

16. Dao, M., Chollacoop, N., Van Vliet, K. J., Venkatesh, T. A., Suresh, S., Computational modeling of the forward and reverse problems in instrumented sharp indentation. Acta Materialia, 2001. 49: p. 38993918.

17. Ogasawara, N., Chiba, N., Chen, X., Representative Strain of Indentation Analysis. Journal of Materials Research, 2005. 20(08): p. 2225-2234.

18. Luo, J., Lin, J., Dean, T. A., A study on the determination of mechanical properties of a power law material by its indentation force-depth curve. Philisophical Magazine, 2006. 86(19): p. 2881-2905.

19. Kang, J.J., Becker, A. A., Sun W., A combined dimensional analysis and optimization approach for determining elastic-plastic properties from indentation test. Journal of Strain Analysis for Engineering Design, 2011. 46: p. 749-759.

20. Kang, J.J., Becker, A. A., Sun W., Determining elastic-plastic properties from indentation data obtained from finite element simulations and experimental results. International Journal of Mechanical Sciences, 2012. 62(1): p. 34-46.

21. Constantinescu, A., Tardieu, N., On the identification of elastoviscoplastic constitutive laws from indentation tests. Inverse Problems in Engineering, 2001. 9: p. 19-44.

22. Chen, X., Ogasawara, N., Zhao, M., Chiba, N., On the uniqueness of measuring elastoplastic properties from indentation: The indistinguishable mystical materials. Journal of the Mechanics and Physics of Solids, 2007. 55(8): p. 1618-1660.

23. Tho, K.K., Swaddiwudhipong, S., Liu, Z.S, Zeng, K., Hua, J., Uniqueness of reverse analysis from conical indentation tests. Journal of Materials Research, 2004. 19(08): p. 2498-2502.

24. Alkorta, J., Martínez-Esnaola, J.M., Sevillano, J.G., Absence of one-to-one correspondence between elastoplastic properties and sharp-indentation load-penetration data. Journal of Materials Research, 2005. 20(02): p. 432-437.

25. Iracheta, O., Bennett, C.J., Sun, W., Characterisation of material property variation across an inertia friction welded CrMoV steel component using the inverse analysis of nanoindentation data. International Journal of Mechanical Sciences, 2016.

26. Bolzon, G., Maier, G., Panico, M., Material model calibration by indentation, imprint mapping and inverse analysis. International Journal of Solids and Structures, 2004. 41: p. 2957-2975.

27. Bolzon, G., Molinas, B., Talassi, M., Mechanical characterisation of metals by indentation test: an experimental verification study for on-site applications. Strain, 2012. 48: p. 517-527.

28. Moy, C.K.S., Bocciarelli, M., Ringer, S.P., Ranzi, G., Identifiction of the material properties of Al 2024 alloy by means of inverse analysis and indentation tests. Materials Science and Engineering A, 2011. 529: p. 119-130.

29. Sargent, P.M., Use of the Indentation Size Effect on Microhardness for Materials Characterization, in Microindentation Techniques in Materials Science and Engineering, P.J. Blau, Lawn, B.R., Editor. 1986, ASTM International: Philadelphia. p. 160-174.

30. ASTM-E8/E8M-15a Standard Test Methods for Tension Testing of Metallic Materials. 2015, ASTM International: West Conshohocken, PA.

31. ISO-14577-1:2015 Metallic materials - Instrumented indentation test for hardness and materials parameters - Part 1: Test method. 2015: 1 rue de Varembé, 1211 Geneva 20 Switzerland. 
32. Liu, Y., Ngan, A.H.W., Depth dependence of hardness in copper single crystals measured by nanoindentation. Scripta Materialia, 2001. 44(2): p. 237-241.

33. Kuhn, H., Dana, M., ASM handbook. Volume 8, Mechanical testing and evaluation. 2000, ASM International: Materials Park, OH.

34. ISO 4287:1997 Geometrical Product Specifications (GPS) -- Surface texture: Profile method -- Terms, definitions and surface texture parameters. 1997: 1 rue de Varembé, 1211 Geneva 20 Switzerland.

35. Yuan, Y. A review of trust region algorithms for optimization. in ICIAM 99. 2000. Edinburgh: Oxford University Press.

36. Coleman, T.F., Y. Li. , An Interior, Trust Region Approach for Nonlinear Minimization Subject to Bounds. SIAM Journal on Optimization, 1996. 6: p. 418-445.

37. Matlab, Optimization Toolbox User's Guide. 2016, The Math Works Inc.: USA.

38. Iracheta, O., A holistic inverse approach on depth-sensing indentation characterisation and its application for predicting residual stresses in multi-phase inertia friction welds. 2017, The University of Nottingham: Nottingham.

39. Liu, L., Ogasawara, N., Chiba, N., Chen, X., Can indentation technique measure unique elastoplastic properties? Journal of Materials Research, 2009. 24(03): p. 784-800.

40. Tho, K.K., Swaddiwudhipong, S., Liu, Z.S, Zeng, K., Simulation of instrumented indentation and material characterization. Materials Science and Engineering: A, 2005. 390(1-2): p. 202-209.

41. Capehart, T.W., Cheng, Y., Determining constitutive models from conical indentation: Sensitivity analysis. Journal of Materials Research, 2003. 18(04): p. 827-832.

42. Waterman, N.A., Ashby, M.F., The Materials Selector. 2nd ed. 1997, London: Chapman \& Hall.

43. Altan, T., Oh, S., Gegel, H.L, , Metal Forming: Fundamentals and Applications. 1983 Metals Park, $\mathrm{OH}$ : ASM International.

44. Tabor, D., The hardness of metals. Oxford Classic Texts in the Physical Sciences. 1951, Oxford: Oxford University Press.

45. Roters, F., Eisenlohr, P., Hantcherli, L., Tjahjanto, D.D., Bieler, T.R., Raabe, D., Overview of constitutive laws, kinematics, homogenization and multiscale methods in crystal plasticity finiteelement modeling: Theory, experiments, applications. Acta materialia, 2010. 58: p. 1152-1211.

46. Griepentrog, M., Ullner, C., Dück, A. Instrumented indentation test for hardness and materials parameter from millinewtons to kilonewtons. in International Conference on Force, Mass, Torque, Hardness and Civil Engineering Metrology in the Age Globalization. 2002. Celle, Germany. 